\title{
Protein-protein interactions define specificity in signal transduction
}

\author{
Tony Pawson ${ }^{1}$ and Piers Nash \\ Program in Molecular Biology and Cancer, Samuel Lunenfeld Research Institute, Mt. Sinai Hospital, Toronto, Ontario \\ M5G 1X5, Canada
}

Virtually every aspect of cellular function within a metazoan organism, including proliferative status, metabolism, gene expression, cytoskeletal organization, and indeed the cell's very survival, is dependent on external signaling molecules, either in the form of soluble hormones or proteins anchored to the surface of an adjacent cell or the extracellular matrix (ECM). These factors exert their effects either by binding receptors displayed on the surface of the cell or, in the case of compounds such as steroids, by traversing the plasma membrane and directly engaging intracellular receptors. In addition, these external signals can be linked to intrinsic cues that regulate events such as polarity and asymmetric cell division, and that monitor the molecular composition of the cell, and therefore determine whether suitable conditions prevail for cell growth and division.

Over the last two decades, we have achieved considerable understanding of the mechanisms by which signals are conveyed from receptors at the plasma membrane to their targets in the cytoplasm and nucleus. At heart, this is a problem of molecular recognition. Hormones must bind selectively to their receptors and these in turn must interact with specific cytoplasmic targets. To understand signal transduction in a general sense, it is important to know whether different biochemical pathways use related molecular devices to control cellular behavior. To understand specificity in signaling, we need to know how receptors interact with particular targets and how the proteins of one pathway can be insulated from related signaling components. At the same time, it is important to learn how distinct signaling pathways communicate with one another, since the entire cell must ultimately function as a single unit whose different elements respond in an organized fashion to external signals. A cell in the body will be exposed to many different stimuli, which it must integrate into a coherent response.

Furthermore, although a rather large fraction of genes within nucleated cells appear to function in the processes of signal transduction and cellular organization (Plowman et al. 1999), it is still remarkable that only a

${ }^{1}$ Corresponding author.

E-MAIL pawson@mshri.on.ca; FAX (416) 586-8869. few thousand gene products can control the sophisticated behaviors of many different cell types. This immediately suggests that signaling proteins must act in a combinatorial fashion, since there are insufficient proteins for each to have a single biological role. For example, there are billions of neurons in the human brain, each of which must project its axon to the appropriate target, let alone undertake the complex biochemical events associated with neurotransmission and synaptic plasticity. Clearly, the signaling molecules that function in the process of axon guidance must act in a combinatorial way to generate the extreme complexity of the human nervous system.

Here we will address some of the underlying biochemical mechanisms through which specificity is generated during signal transduction, and pursue the means by which signaling molecules may act in combination to generate complex biological responses.

\section{Specificity and complexity at the level of receptors}

The mechanisms of receptor activation have been intensively studied through the analysis of receptor tyrosine kinases (RTKs), which possess a single membrane-spanning region, and related multisubunit receptors, such as those for cytokines and antigens that signal through associated cytoplasmic tyrosine kinases (Hunter 2000). The binding of a hormone to such receptors induces either receptor oligomerization (Heldin et al. 1995; Plotnikov et al. 1999) or the spatial reorientation of preclustered chains, as shown for the erythropoietin receptor (Remy et al. 1999). As a consequence, ligand binding to a RTK promotes the intermolecular autophosphorylation of one receptor chain by its neighbor, usually within the activation segment of the kinase domain (Hubbard 1997). This results in displacement of the activation segment from the active site. The stimulated kinase domain then phosphorylates additional tyrosine residues, usually within noncatalytic regions of the receptor, which provide docking sites for downstream targets.

The exclusive binding of a single growth factor to an individual receptor is more likely the exception than the rule. Indeed, the oligomeric nature of activated receptors allows the formation of receptor complexes composed of distinct, albeit closely related subunits, which can have different signaling potentials (Pinkas-Kramarski et al. 
1998). As a simple example, platelet-derived growth factor (PDGF) is a covalently linked dimer composed of A or B chains in different combinations, which induces the formation of a receptor dimer similarly composed of $\alpha$ or $\beta$ chains (Heldin et al. 1998). Because the B chain of PDGF only binds the $\beta$ receptor, whereas both $A$ and $B$ PDGF bind the $\alpha$ receptor, different dimeric forms of PDGF induce distinct combinations of receptor chains. Interestingly, the signaling properties of the $\alpha$ and $\beta$ receptor chains differ from one another, since the $\alpha / \beta$ PDGF receptor heterodimer is more potent in stimulating mitogenesis that either of the homomeric receptors. This correlates with a failure of the $\alpha / \beta$ receptor to bind Ras GTPase activating protein, a negative regulator of the Ras GTPase, resulting in enhanced activation of the Ras-MAP kinase (MAPK) pathway (Ekman et al. 1999).

Yet more diversity can be seen in the four members of the ErbB RTK family, which bind several ligands, including epidermal growth factor (EGF) and the neuregulins (NRG). Although all possible dimeric combinations of receptors can form, ErbB2, which itself does not bind ligands with high affinity, is a preferred heterodimeric partner (Pinkas-Kramarski et al. 1998). A biological requirement for heterodimer formation is revealed by the observation that mutations in the ErbB2 and ErbB4 receptors, and the NRG-1 ligand, give essentially identical phenotypes in mouse embryos (Gassmann et al. 1995; Lee et al. 1995; Meyer and Birchmeier 1995). Different receptor chains have distinct cytoplasmic binding sites for intracellular signaling proteins and as a result give distinct signaling outputs, as measured by the strength of MAPK activation. Of interest, ErbB3 lacks intrinsic catalytic activity, but is trans-phosphorylated by a kinase-active partner such as ErbB2, and thus serves a scaffolding function through its ability to bind cyotplasmic targets. Indeed, the ErbB2/ErbB3 heterodimer is potently mitogenic (Waterman et al. 1999).

It is common for a single receptor to bind and be activated by more than one extracellular ligand. For example, the prolactin cytokine receptor can engage both growth hormone and prolactin. Structural and mutagenesis analysis has indicated that the ligand-binding sites of cell surface receptors may be rather adaptable, composed of relatively hydrophobic yet solvent accessible surfaces (Cunningham and Wells 1991; Lowman et al. 1991). Although the ligand-binding surfaces are quite large, only a few residues are critical for ligand recognition. In the example cited above, the two hormones recognize overlapping sites on the same receptor, but are dependent on distinct residues for high affinity binding. Such data suggest that receptors combine selectivity for specific ligands with the potential for flexibility and possibility for rapid evolution of hormone recognition. As discussed below, protein-protein interactions within the cell that control cytoplasmic signaling pathways display many of the same characteristics.

In addition to the formation of multichain receptors through the interactions of distinct subunits, recent data suggest that entirely different receptors may directly interact with one another at the surface of the same cell.
This leads to the possibility of cross-talk between separate receptors and pathways at the very earliest steps in signaling. In the nervous system, the $\gamma$ chain of the heteropentameric $\mathrm{GABA}_{\mathrm{A}}$ receptor, which is a ligand-gated ion channel, physically interacts through a cytoplasmic loop with the carboxy-terminal region of the dopamine D5 receptor, a seven transmembrane-spanning G protein-coupled receptor (GPCR) that links to Gs and the production of cAMP (Liu et al. 2000). This association leads to a mutual inhibition of the two receptors and provides a mechanism through which a GPCR may influence synaptic strength independently of G protein signaling. Similarly, neurotrophins acting through Trk family RTKs can rapidly induce action potentials in CNS neurons, suggesting that Trk receptors may interact with a $\mathrm{Na}^{+}$channel (Kaffitz et al. 1999). These types of interaction are not confined to the nervous system. For example, the Kit RTK, which is activated by the hematopoietic stem cell factor, can bind and phosphorylate the cytoplasmic region of the erythropoietin cytokine receptor (Wu et al. 1995).

\section{Specific activation of signaling pathways-protein domains and motif recognition}

The involvement of modular protein-protein interactions in signaling from cell surface receptors was originally recognized in the context of RTKs. As noted above, receptor activation leads to the intermolecular phosphorylation of receptor chains at sites that consequently bind proteins with SH2 domains (Pawson 1995; Kuriyan and Cowburn 1997). SH2 domains are protein modules of $\sim 100$ amino acids that recognize phosphotyrosine residue-containing peptides in the context of 3-6 carboxyterminal amino acids (Eck et al. 1993; Waksman et al. 1993; Pascal et al. 1994). As with many interaction modules, the amino and carboxyl termini of SH2 domains are close together in space, and on the opposite face from the ligand-binding surface. This potentially allows an $\mathrm{SH} 2$ domain to be inserted into a host protein at an internal location, while leaving the phosphopeptide-binding surface free to engage ligands. Most SH2 domains require phosphorylation of the peptide ligand for high affinity binding, but differ in their ability to recognize residues carboxy-terminal to the pTyr, thereby imbuing each SH2 domain with an ability to bind preferentially to a specific phosphorylated motif (Songyang et al. 1993). Thus, in the case of activated RTKs, their ability to stimulate cytoplasmic signaling pathways is to some extent determined by the sequence contexts of their autophosphorylation sites, which in turn dictates which SH2-containing proteins will engage the autophosphorylated receptor.

SH2 domains must therefore achieve something of a balancing act. Their affinity for an unphosphorylated site must not be too high, or binding could not be regulated by phosphorylation, yet they must gain sufficient binding energy from the recognition of more carboxy-terminal residues to allow discrimination between different sites. Furthermore, their off-rates must be sufficiently 
high to allow for rapid signal transduction. Perhaps for this reason the interactions of $\mathrm{SH} 2$ domains with phosphopeptide motifs can be highly dynamic (Kay et al. 1998). For example, although the SH2 domains of phospholipase C (PLC)- $\gamma 1$ and the Shp2 tyrosine phosphatase both bind pTyr followed by five hydrophobic residues, the PLC- $\gamma 1$ SH2-C domain obtains more binding energy from electrostatic interactions involving the pTyr, whereas the Shp2 SH2-N domain has larger contributions from the hydrophobic interface. Strikingly, although the PLC- $\gamma 1$ SH2 domains show strong selectivity at the +1 to +5 positions, the $\mathrm{SH} 2$ domain residues lining the hydrophobic groove that accommodates these amino acids show significant motional disorder even following ligand binding. This leads to the possibility that SH2 domain binding specificity results from a combination of permissive and inhibitory forces. Thus compatible residues in the SH2 domain and ligand will promote binding, whereas residues that sterically interfere with phosphopeptide recognition will inhibit recognition. Consistent with this view, the SH2 domains of PLC- $\gamma 1$ can potentially bind a site with a pYXXM motif, that normally accommodates phosphatidylinositol 3'-kinase (PI3K), but are excluded from such a site by a Ser at the +4 position, as found in physiological PI3K-binding sites on the $\beta$ PDGF receptor (Larose et al. 1995).

The potential flexibility of $\mathrm{SH} 2$ domains is emphasized by the ability of single amino acid substitutions to alter binding specificity (Fig. 1). SH2 domains generally fall into three classes: PLC- $\gamma$-like SH2 domains bind phosphopeptides as an extended strand, with carboxyterminal residues fitting into a hydrophobic cleft. Srclike SH2 domains are similar, but have a flat binding surface that selects for charged residues at the +1 and +2 positions, while the sidechain of the +3 residue fits into a hydrophobic pocket. In contrast, the Grb2 SH2 domain has a bulky Trp sidechain that blocks the progress of the phosphopeptide ligand, which is forced into a $\beta$ turn, best accommodated by a +2 Asn. Surprisingly, it is possible to convert a PLC- $\gamma$ SH2 domain to a Src-like specificity by changing a single Cys residue (at the $\beta \mathrm{D} 5$ position) to Tyr (Songyang et al. 1995). Similarly the Src SH2 domain can be converted to a Grb2-like specificity by altering a Thr (at the EF1 site) to Trp. This mutant Src SH2 domain mimics Grb2 at the structural level, and functions in Caenorhabditis elegans development as if it were a Grb2 SH2 domain (Marengere et al. 1994). This apparent flexibility may have an evolutionary advantage, in the sense that SH2 domain binding specificity might change rather rapidly, allowing the formation of new signaling connections as metazoan organisms became more complex.

The relevance of specific SH2 domain-mediated interactions to biological signaling pathways has also been tested by introducing mutations into $\mathrm{SH} 2$ docking sites on receptors. A nice example is provided by the EGF receptor homolog in C. elegans, LET-23, which is required for vuval differentiation, viability and ovulation (Lesa and Sternberg 1997). LET-23 has eight potential autophosphorylation sites within its carboxy-terminal

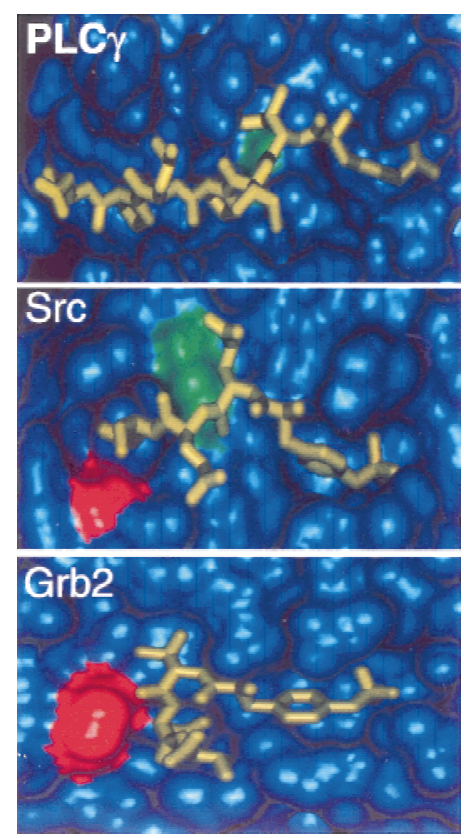

Figure 1. Evolution of $\mathrm{SH} 2$ domain-binding specificity. The surfaces of the PLC- $\gamma 1$, Src, and Grb2 SH2 domains are shown in blue, with their corresponding peptide ligands (pYIIPLPD, pYEEI, pYVNV, respectively) shown in yellow. In each case the pTyr is to the right. For PLC- $\gamma 1$, the +1 Ile of the ligand fits into the start of a hydrophobic groove, framed by a Cys ( $\beta D 5)$ shown in green. In the Src SH2 domain this Cys is replaced by a Tyr (in green) which makes a flat surface that selects for charged residues in the +1 and +2 positions. Src has a pocket that accommodates the hydrophobic side chain of the +3 Ile, which is formed in part by a Thr (EF1) shown in red. In the Grb2 SH2 domain this Thr is replaced by a Trp (in red) which fills up the pocket and forces the phosphpeptide into a $\beta$-turn. Changing the Cys in PLC- $\gamma 1$ to Tyr converts the PLC- $\gamma 1$ SH2 domain to a Src-like specificity, and conversely changing the Thr in Src to Trp results in a Grb2-like specificity.

tail, with binding motifs for $\mathrm{SH} 2$ proteins such as Grb2, PLC- $\gamma$, and SLI-1 (the worm homolog of mammalian cCbl). The three carboxy-terminal autophosphorylation sites (Y6-8) lie in YXN motifs that can bind the worm Grb2 adaptor and thereby activate the Ras pathway. These sites have a redundant role in vulval formation and viability but are not required for ovulation. In contrast, the Y5 site, which likely signals through PLC- $\gamma$ to activate the inositol triphosphate $\left(\mathrm{IP}_{3}\right)$-receptor and elevate intracellular calcium, has a unique role in ovulation. Furthermore, the Y2 site inhibits LET-23 signaling, potentially through the SLI-1/c-Cbl SH2 protein, which likely acts as an E3 protein-ubiquitin ligase (Joazerio et al. 1999).

In the mammalian system, the Met receptor tyrosine kinase has two closely spaced Tyr phosphorylation sites within its carboxy-terminal tail, that bind a number of SH2-containing proteins. Substitution of both Tyr residues with Phe in the mouse causes embryonic lethality similar to that seen with a null allele, suggesting that although the receptor retains kinase activity, it is func- 
tionally impotent when stripped of its SH2-docking sites (Maina et al. 1996). In contrast, a Met receptor with a more subtle substitution that alters a +2 Asn crucial for Grb2-binding has a milder phenotype, involving defects in muscle development. Similarly, substitution of Tyr 719 in the mouse Kit RTK, that normally engages PI3K, impairs specific aspects of Kit function required for the survival of male germ cells (Blume-Jensen et al. 2000), and ovarian follicle development (Kissel et al. 2000). However, PI3K-binding is not significantly required for Kit's role in melanogenesis and hematopoiesis. In a similar vein, substitutions of the PI3K binding sites (Tyr 739/ 750 ) in the mouse $\beta$ PDGF receptor cause a very subtle phenotype, resulting in decreased chemotaxis and ability to contract a collagen gel in culture, and a failure to normalize interstitial fluid pressure in vivo (Heuchel et al. 1999). These data are consistent with the view that individual receptor phosphorylation sites bind $\mathrm{SH} 2$ signaling proteins in a sequence-dependent manner, resulting in the activation of defined biochemical pathways and specific biological responses.

There are a number of complications to this simple view. First, different signaling pathways may ultimately converge on overlapping targets, and thus have partially redundant functions (Fambrough et al. 1999). Second, some signaling pathways may have subtle biological activities. Furthermore, some RTKs can phosphorylate specific docking proteins at residues that subsequently bind $\mathrm{SH} 2$ proteins, and provide signaling activity even in the absence of SH2-binding sites on the receptor itself. Examples include the Shc, IRS-1, and FRS2 proteins. These characteristically possess a means of membrane attachment, a receptor-binding PTB domain, and mul- tiple sites for tyrosine phosphorylation and SH2-binding (Sun et al. 1993; van der Geer et al. 1996; Kouhara et al. 1997).

It is instructive to consider how these docking proteins are recruited to activated receptors. Their PTB domains specifically recognize pTyr-containing motifs, although in an entirely different way from SH2 domains (Zhou et al. 1995), and preferentially bind phosphorylated NPXY elements in the receptor's juxtamembrane region (Trub et al. 1995; van der Geer et al. 1995). Interestingly, a growing number of proteins have been found to possess PTB domains that bind NPXY, or related, motifs but do not require phosphorylation for high affinity binding (Borg et al. 1998). This has led to the notion that PTB domains originally evolved to recognize non-phosphorylated peptide motifs, and subsequently developed a capacity for pTyr-binding in specific cases. Indeed, the PTB domain of FRS2 binds both to a phosphorylated NPXY site on the activated TrkA neurotrophin receptor, and to an entirely different non-phosphorylated site on the FGF-receptor (Ong et al. 2000) (Fig. 2). Rather strikingly, PTB domains have a similar structural fold to $\mathrm{PH}$ domains (which bind phospholipids) and EVH1 domains (which bind proline-rich motifs), as well as to a protein that binds the Ran GTPase, suggesting that this is a rather versatile scaffold that has been exploited for several different protein and phospholipid recognition events (Yoon et al. 1994; Prehoda et al. 1999; Vetter et al. 1999).

What purpose is served by docking proteins that associate with RTKs? One possibility is that they amplify signaling from a given receptor to a particular biochemical pathway. Phosphorylation of IRS-1 by the insulin re-
Figure 2. Modular protein-protein interaction domains convey signals from activated receptors using a variety of recognition motifs. Both the TNF and FGF receptors employ modular protein-protein interaction domains to convey signals. The activated TNF-R1 trimer binds a docking protein, TRADD, through death domain (DD)-DD interactions. TRAD, in turn, binds to a variety of adaptors, including FADD, TRAFs, and RIP. FADD recruits procaspase 8, which initiates a proteolytic cascade resulting in apoptosis. Recruitment of TRAF-2 via the TRAF-C domain initiates the Jnk pathway, whereas recruitment of RIP activates NFKB signaling. In an analogous manner, the FGF-R is clustered by FGF and proteoglycan. The myristoylated FRS2 scaffold protein binds to the FGF-R through its PTB domain, becomes phosphorylated on multiple tyrosines, and consequently binds the SH2 proteins Grb2 and Shp2. The Grb2 adaptor recruits Sos1 through its $\mathrm{SH} 3$ domain, and Sos1 acts as a GEF for the Ras GTPase. Activated Ras can potentially stimulate multiple pathways to promote cell survival, activate transcription, or cause cytoskeletal rearrangement.

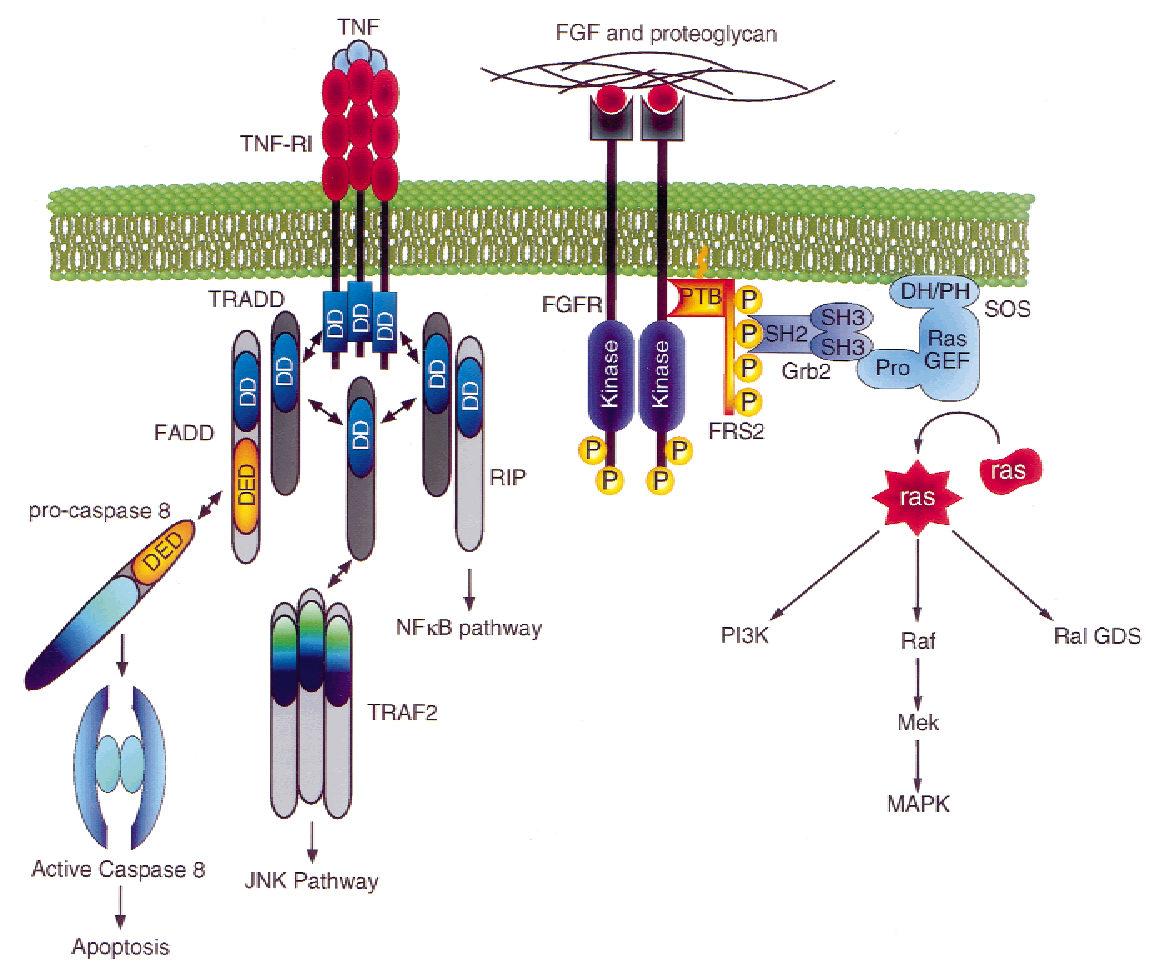


ceptor creates multiple binding sites for PI3K, whereas Shc and FRS2 primarily engage Grb2, and thus are principally involved in activating the MAPK pathway. Another role for a docking protein may be to juxtapose cytoplasmic proteins that act at successive stages of a pathway. An example is provided by the SLP-76 protein that functions downstream of the $\mathrm{T}$-cell antigen receptor. SLP-76 is an SH2 protein that is recruited to the T-cell receptor target LAT through an $\mathrm{SH} 2 / \mathrm{SH} 3$ adaptor protein, GADS. SLP-76 is then phosphorylated at multiple sites by the receptor-associated kinase ZAP-70, and consequently binds SH2 proteins (Liu et al. 1999). One such binding protein is Vav, which acts as a guanine nucleotide exchange factor (GEF) to activate the Rac GTPase. SLP-76 also binds the SH2/SH3 adaptor Nck, which complexes through its $\mathrm{SH} 3$ domains with the serine/ threonine kinase Pak. Pak is activated by GTP-bound Rac (produced by Vav) and induces cytoskeletal re-organization. SLP-76 therefore functions as a scaffold that juxtaposes members of a pathway targeting the cytoskeleton (Bubeck Wardenburg et al. 1998).

\section{Multiple modules in signal transduction}

$\mathrm{SH} 2$ domains serve as a prototype for a large and growing family of modular protein domains found in intracellular signaling proteins (see http://smart.embl-heidelberg. de/) (Schultz et al. 2000). In addition to domains involved in the recognition of pTyr- and pSer/Thr-containing peptides, there are a series of modules that recognize specific proline-rich peptide motifs, including $\mathrm{SH} 3, \mathrm{WW}$, and EVH1 domains (Niebuhr et al. 1997; Nguyen et al. 1998; Aghazadeh and Rosen 1999). EH domains recognize Asn-Pro-Phe sequences, commonly found in polypeptides involved in protein trafficking (Salcini et al. 1997; Mayer 1999|, whereas PDZ domains bind short peptide motifs at the extreme carboxyl termini of proteins, typically transmembrane receptors (Songyang et al. 1997). Two folded PDZ domains can also bind directly to one another (Hillier et al. 1999), and SAM domains also appear to have an intrinsic capacity to undergo selfoligomerization (Stapleton et al. 1999; Thanos et al. 1999). As well as modules involved in domain-peptide or domain-domain interactions, there are several examples of domains that bind selectively to phospholipids and thereby target proteins to specific sites in the membrane to directly regulate their activity or access to substrates. In particular, FYVE domains frequently bind specific phosphoinositides, and therefore thereby mediate the effects of PI kinases on cellular behaviour (Fruman et al. 1999; Rameh and Cantley 1999). Recent evidence suggests that the homodimerization of PH and FYVE domains may increase the avidity with which they bind membrane sites (Mao et al. 2000).

In many cases, cytoplasmic signaling proteins possess multiple protein-protein and protein-phospholipid interaction domains, covalently linked in various combinations. The joining of different domains can serve a variety of functions. Two domains may interact with different sites on the same target, as commonly occurs with polypeptides that possess tandem SH2 domains, thereby increasing both the affinity and specificity of the interaction (Ottinger et al. 1998). Conversely, separate domains may interact with distinct partners, as observed for adaptors with SH2 and SH3 domains, such as Grb2 that links activated receptors to downstream targets with proline-rich motifs, notably the Ras GEF Sos1 (Li et al. 1993; Rozakis-Adcock et al. 1993) (Fig. 2). Furthermore, modular domains can engage in complex intramolecular interactions that regulate the enzymatic activities of their host protein, as occurs in the Src family kinases or the Shp2 tyrosine phosphatase (Sicheri et al. 1997; Xu et al. 1997; Hof et al. 1998). These roles are not necessarily mutually exclusive. In the Src tyrosine kinase, phosphorylation of a carboxy-terminal tyrosine leads to intramolecular interactions in which the $\mathrm{SH} 2$ and $\mathrm{SH} 3$ domains engage internal ligands and block kinase activity. However, once these intramolecular interactions are broken, the $\mathrm{SH} 3$ and $\mathrm{SH} 2$ domains play an important role in tethering Src to its substrates and in promoting processive phosphorylation (Sakai et al. 1994; Pellicena et al. 1998).

\section{Generality of protein-protein interactions in signaling}

\section{TGF $\beta$ receptors}

The process through which protein-protein interactions mediate phosphotyrosine signaling represents a specific aspect of a more general process in signal transduction. Members of the TGF $\beta$ receptor family exert their effects through type 1 and type II receptors with protein serine/ threonine kinase activity (Massague 1998). Binding of TGF $\beta$ causes the type II receptor to phosphorylate the type I receptor, which is thereby induced to phosphorylate downstream targets, the regulated (R-) Smads, at three carboxy-terminal sites within an SSXS motif. The Smad proteins have an amino-terminal MH1 domain, a central linker, and a carboxy-terminal MH2 domain, which recognizes the type I receptor. R-Smad phosphorylation appears to block an internal interaction between the MH1 and MH2 domains, and free the MH2 domain to associate with the so-called common Smad (Smad4), which is not itself phosphorylated. A binding site has been identified on Smad4 that may serve as a receptor for phosphorylated residues of R-Smads (Qin et al. 1999) The resulting $\mathrm{R}-\mathrm{Smad} / \mathrm{Smad} 4$ hetero-oligomeric complex is retained in the nucleus, where it binds to specific promoters through the $\mathrm{MH} 1$ domain and to additional transcription factors such as FAST (Wrana 2000) (Fig. 3).

There are a number of additional regulatory steps that likely contribute to biochemical and biological specificity in TGF $\beta$ signaling. First, a docking protein termed SARA binds the $\mathrm{MH} 2$ domain of unphosphorylated Smad 2 and Smad3 and appears to colocalize with the TGF $\beta$ receptor (Tsukazaki et al. 1998; Wu et al. 2000). SARA thereby enhances TGF $\beta$ signaling by increasing the specificity and efficiency with which the receptor phosphorylates its targets. Phosphorylated Smads are released from their SARA anchor. Interestingly, in addi- 
Figure 3. Stats and Smads: Linking receptors to transcription. IFN $\gamma$ receptor activation induces protein-tyrosine kinases of the Jak family. These act on the cytoplasmic tail of the receptor, creating $\mathrm{SH} 2$ docking sites. STAT proteins are recruited to the membrane via their SH2 domain, and are themselves phosphorylated by the Jak kinases. Phosphorylated STATs dimerize and translocate to the nucleus where they activate transcription by binding directly to specific DNA sequences. In a somewhat anlogous manner, R-SMADs are recruited to activated TGF $\beta$ receptors from their membrane anchor protein SARA. Following phosphoylation, the R-SMAD protein forms heterodimers with SMAD4 and translocates to the nucleus.

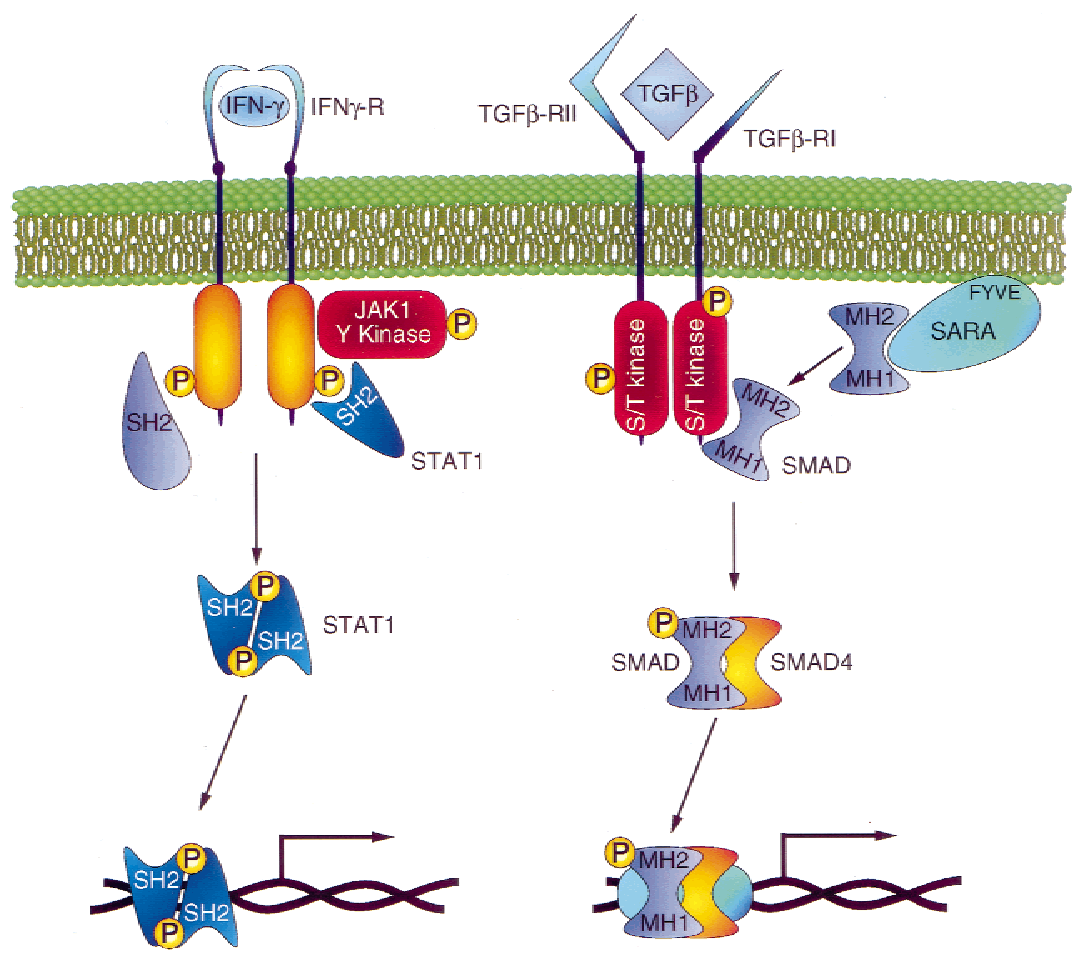

tion to the Smad-binding region, SARA has a FYVE domain that recognizes PI-3-P, and may therefore direct the Smad to a particular membrane site where it encounters the receptor.

Although there are many differences in the details between RTK and TGF $\beta$ receptor signaling, there are also a number of parallels. The receptor targets are modular and they form complexes with their receptors. In both cases, phosphorylation regulates protein-protein interactions, although in distinct ways. In addition, both RTKs and TGF $\beta$-receptors can employ docking proteins with phospholipid- and protein-interaction domains, that aid in the recruitment of targets to the receptor. Indeed, the regulation of Smad signaling is somewhat reminiscent of Stats, SH2-containing proteins that function downstream of cytokine receptors to control gene expression (Darnell 1997) (Fig. 3). Stats bind to specific sites on activated cytokine receptors through their SH2 domain, and themselves become phosphorylated, resulting in a mutual SH2-pTyr interaction between two Stat molecules (Chen et al. 1998). The phosphorylated Stats consequently dimerize, are displaced from the receptor, relocate to the nucleus and bind to specific promoters.

There are also similarities in the way that RTK and TGF $\beta$ receptor signaling pathways are inhibited. As noted above, RTKs such as the $\beta$ PDGF receptor can bind the $\mathrm{SH} 2$-containing protein $\mathrm{c}-\mathrm{Cbl}$, which acts as an E3 protein-ubiquitin ligase to label the receptor for degradation. Within their linker region, Smads have prolinerich (PY) motifs that bind the WW domains of another E3 protein-ubiquitin ligase (Smurf) with a Hect catalytic domain, leading to Smad ubiquitination and destruction (Zhu et al. 1999). Thus in both cases modular protein interactions target specific components of the signaling pathway for degradation, in a fashion that appears critical for appropriate biological responses.

\section{TNF receptor signaling}

Members of the tumor necrosis factor (TNF) receptor family lack catalytic domains, but use specific proteinprotein interactions to convey signals from the receptor to their downstream targets. A relatively simple example involves the Fas receptor, which induces cell death upon stimulation with the Fas-ligand (Ashkenazi and Dixit 1998). Fas has a carboxy-terminal death domain (DD), which interacts specifically with a related DD at the carboxyl terminus of the adaptor protein FADD /Chinnaiyan et al. 1995). FADD has an amino-terminal death effector domain (DED), which in turn recognizes the DED of procaspase 8 (Muzio et al. 1996). Oligomerization of Fas by Fas-L appears to juxtapose chains of procaspase 8 which consequently undergo auto-cleavage, leading to the release of active caspase 8 , initiating a cascade of proteolytic events that result in apoptosis (Salvesen et al. 1999). Thus, rather like a RTK that engages a modular protein (Grb2), which in turn recruits a signaling enzyme (Sos1) to activate the Ras pathway, so Fas binds a modular adaptor, FADD, that couples to the enzyme caspase 8 and lights the apoptotic fuse. These data indicate that receptors involved in signaling pathways that do not use phosphorylation as a primary mechanism for information transfer, nonetheless make use of modular protein-protein interactions to specifically activate their targets.

Other members of the TNF-R superfamily, such as TNF-R1, utilize a death domain to activate cytoplasmic 
signaling. TNF-R1 interacts initially with the death domain of a scaffolding protein termed TRADD (Hsu et al. 1995), which in turn recognizes the FADD adaptor, as well as a distinct modular protein termed TRAF2 that activates the Jnk MAPK pathway, and a DD-containing protein kinase RIP that stimulates the NFkB pathway (Arch et al. 1998) (Fig. 2). Thus TNF-R1, like some RTKs, employs a docking protein that associates with multiple downstream targets and can thereby extend the range and potency of receptor signaling. However, most members of the TNF-R family, including TNF-R2, appear to signal primarily through TRAF proteins. The TRAFs contain a carboxy-terminal domain (TRAF-C) that binds short peptide motifs on the relevant receptor or on docking proteins such as TRADD, preceeded by a coiled-coil region. The amino termini of the TRAFs have ring and zinc finger sequences that are responsible for interactions with downstream targets (Rothe et al. 1994). Crystal structures of the coiled-coil and TRAF-C regions of TRAF2 indicate that these domains self-associate to form a trimer that is ideally fashioned to bind the activated receptor, which is itself coralled into a trimeric state by its ligand (McWhirter et al. 1999; Park et al. 1999; Ye et al. 1999). Thus, although TRAFs have only a low affinity for the monomeric receptor, they bind in a co-operative fashion to the oligomerized receptor. Surprisingly, an individual TRAF-C domain can bind through the same groove to peptide motifs that are unrelated in their primary sequences. Thus, by analogy with RTKs and SH2 domains, the oligomerization of TNF-Rs creates high affinity binding sites for the TRAF-C domains, which recognize specific motifs within the receptor. TRAFs then act as adaptors to link the activated receptors to cytoplasmic targets.

\section{Specificity in signaling by serine/threonine kinases}

RTKs and other cell surface receptors, frequently activate protein serine/threonine kinases that convey the signal to targets in the cytoplasm and nucleus. Clearly, this is an intrinsic function of the TGF $\beta$ receptors, but other receptors must take a more circuitous route to stimulate protein serine/threonine kinase activity. The Ras GTPase, activated by RTKs, binds the c-Raf protein kinase (a MAPK kinase kinase or MAPKKK), which consequently phosphorylates Mek (a MAPKK). Mek is a dual-specificity kinase that phosphorylates and activates Erk (a MAPK), which has multiple substrates involved in the regulation of cell growth and proliferation (Marshall 1994; Whitmarsh and Davis 2000). Similar cascades of protein kinases lead to the activation of other MAPKs, such as Jnk/Sap or p38.

RTKs can also stimulate protein serine/threonine kinases through pathways involving phospholipid production, including the activation of $\mathrm{PI} 3 \mathrm{~K}$, which leads to the production of PI-3,4,5-P3. PIP3 binds selectively to the $\mathrm{PH}$ domains of the serine/threonine kinases PDK1 and Akt/PKB (Alessi et al. 1997; Belham et al. 1999) inducing their membrane association (Andjelkovic et al. 1999). In- terestingly, PDK1 phosphorylates PKB within the activation loop of the catalytic domain, in a fashion that is indispensable for PKB activation and its subsequent effects on events such as cell survival. Furthermore, PDK1 appears to be a more general activator of a family of serine/threonine kinases, including p70S6 kinase, p90Rsk1, and atypical protein kinase C (PKC) isoforms, amongst others. PLC- $\gamma$ also regulates signaling to PKCs by stimulating the hydrolysis of PI-4,5- $\mathrm{P}_{2}$ to yield diacyglycerol and $\mathrm{IP}_{3}$, which contribute to the activation of conventional PKCs.

Through a series of protein-protein interactions, described in part above, TNF-R1 activates a heteromeric complex comprised of two protein kinase subunits, IKK $\alpha$ and IKK $\beta$ and at least one additional component, IKK $\gamma /$ Nemo (Rothwarf et al. 1998; Karin 1999). IKK activation leads to the phosphorylation of IкB, an inhibitor of the $\mathrm{NF} \kappa \mathrm{B}$ transcription factor, resulting in IкB proteolytic destruction. This frees NFkB to enter the nucleus and induce the expression of specific genes.

The theme that numerous cell surface receptors activate pathways involving a series of protein serine/threonine kinases raises the issue of how specificity is maintained in such kinase cascades, and how the ultimate phosphorylation of target proteins on serine/threonine modifies their functional properties. The pursuit of the latter question has uncovered a number of modular proteins that physically recognize specific phosphorylated serine/threonine-containing motifs, in a similar fashion to the binding of SH2 or PTB domains to pTyr-containing proteins. 14-3-3 proteins provide the prototype for this idea. Mammalian cells contain seven 14-3-3 isoforms, which form homo- or heterodimers that recognize specific pSer-containing motifs, originally identified as having the consensus Arg-Ser-X-pSer-X-Pro (Muslin et al. 1996). More recent data have revealed the structural basis for this interaction (Yaffe et al. 1997). Of particular interest, some of the proteins involved in the signaling pathways mentioned above are bound by 14-3-3 proteins following their phosphorylation. The protein kinase $\mathrm{PKB}$, for example, phosphorylates the pro-apoptotic proteins BAD and FKHRL1, the former being a Bcl family member that in its unphosphorylated state binds and inhibits the death antagonist Bcl-X $\mathrm{L}_{\mathrm{L}}$ (Zha et al. 1996), while FKHRL1 is a transcription factor that may induce the expression of pro-apoptotic genes (Brunet et al. 1999). The binding of 14-3-3 proteins to phosphorylated targets apparently results in their relocalization and inhibition. In the case of $\mathrm{BAD}$ this is achieved by sequestering it away from Bcl- $\mathrm{X}_{\mathrm{L}}$, while FKHRL1 is apparently retained in the cytoplasm once complexed to 14-3-3, and is therefore prevented from gaining access to its targets in the nucleus. 14-3-3 proteins also interact with the c-Raf kinase to regulate its activity (Thorson et al. 1998), and indeed a dominant negative 14-3-3 protein blocks seruminduced Erk MAPK activation and enhances apoptosis both in cultured cells and in mice (Xing et al. 2000).

The ability of 14-3-3 proteins to control cellular events through the recognition of specific phosphoproteins is not restricted to conventional signaling pathways re- 
sponsive to extrinsic cues, but is also important in regulating checkpoints in the cell cycle that monitor intrinsic events such as DNA damage. In this context, a key step in controlling the passage of mammalian cells through the cell cycle is the serine phosphorylation of Cdc25C, a tyrosine phosphatase that dephosphorylates and activates the critical cyclin-regulated protein kinase $\mathrm{Cdc} 2$, and thereby promotes passage of the cell into mitosis. During interphase Cdc25C is phosphorylated at Ser-216, resulting in binding to $14-3-3$ proteins (Peng et al. 1997). Cdc25C shuttles between the cytoplasm and nucleus, and 14-3-3 binding favors the retention of Cdc25C in the cytoplasm, possibly by masking a nuclear localization signal (Fig. 4). As a result Cde25C is physically separated from its nuclear substrate, which is therefore held in an inactive state. Dephosphorylation of Ser-216 frees Cdc25C to enter the nucleus and initiate mitosis. In yeast, protein kinases that regulate cell cycle checkpoints by responding to DNA damage and replication blocks, such as Cds1 and Chk1, directly phosphorylate Cdc25 and induce a Cdc25/14-3-3 complex, thereby slowing passage through the cell cycle and allowing time for DNA repair (Zeng et al. 1998; Zeng and PiwnicaWorms 1999).

14-3-3 proteins are small, individual polypeptides, and have not as yet been found to be covalently linked to other functional domains. However, there are protein modules with the potential to bind pSer/pThr-containing motifs that, like SH2 domains, are located within a number of different host proteins. Notably, the Forkhead-associated (FHA) domain is present in a wide range of nuclear polypeptides involved in transcription, DNA repair or cell cycle progression in both eukaryotes and prokaryotes (Hofmann and Butcher 1995). Recent work on the yeast protein kinase Rad53 has shown that its amino-terminal FHA domain binds selectively to pThr$\mathrm{X}$-X-Asp motifs and has suggested that the recognition of phosphorylated peptide motifs may be a common property of FHA domains (Durocher et al. 1999). The structure of the carboxy-terminal PHA domain of Rad53 has recently been solved, revealing a $\beta$-sandwich with two anti-parallel $\beta$-sheets (Liao et al. 1999), but the precise mechanism of ligand binding is unknown. Interestingly, Rad53 lies downstream of its phosphorylated binding partner, Rad9, a protein that senses DNA damage, suggesting that a phosphodependent FHA-mediated interaction is important in checkpoint signaling (Sun et al. 1998). Consistent with this idea, recent data indicate that the amino-terminal FHA domain of human Chk2, a homolog of yeast Rad53, is affected by mutations in the familial cancer Li-Fraumeni syndrome (Bell et al. 1999).

There are increasing examples of pSer/pThr-dependent protein-protein interactions. Phosphorylation of the transcription factor CREB at Ser-133 by protein kinases such as cAMP-dependent protein kinase (PKA), $\mathrm{PKB}$, and p90Rsk2 creates a binding site for the coactivator CBP, and results in transcriptional activation of CREB-responsive genes (Xing et al. 1996; Radhakrishnan et al. 1997; Du and Montminy 1998). Similarly, the WW domain of the peptidyl-prolyl isomerase Pin1 binds pSerPro motifs, which may position the enzyme close to its substrates (Lu et al. 1999).

Equally striking, the pSer/Thr-dependent recognition of proteins by members of the F-box family appears to be

Figure 4. A simplified scheme indicating the role of serine/threonine phosphorylation events in regulating DNA damage-induced cell cycle checkpoint control. DNA damage results in phosphorylation mediated stabilization of $\mathrm{p} 53$ by a variety of kinases (ATM, ATR, DNA-PK, Jnk, and CKI). This blocks the interaction of p53 with $\mathrm{Mdm} 2$ that normally results in efficient ubiquitin-targeted degradation of p53 by the proteasome. Activated p53 induces the transcription of genes such as p21Cip/Waf, a cyclin dependent kinase inhibitor that blocks the action of CyclinE/ Cdk2 and thereby prevents the phosphorylation of targets such as $\mathrm{Rb}$, an event that is required for $\mathrm{G}_{1}$-to-S transition. DNA damage stabilization of $\mathrm{p} 53$ thereby blocks cell cycle progression at the $\mathrm{G}_{1}$-to-S checkpoint. Cyclin E1 is itself degraded at the $\mathrm{G}_{1}$-to-S boundary following phosphorylation on Thr-380. Phosphorylation at this site is sufficient to target Cyclin E1 to the SCF E3 ubiquitin ligase complex composed of Cdc53/CUL-1, Skp1, Rbx-1,

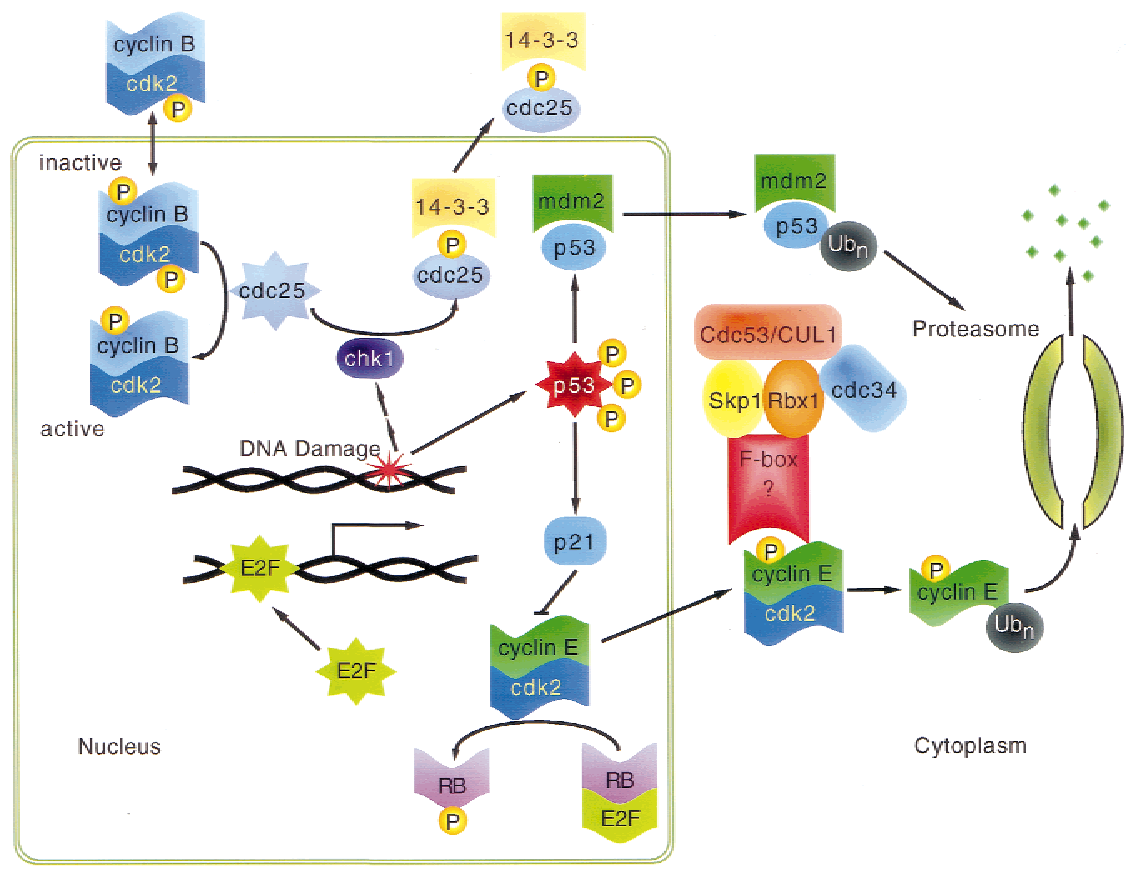
Cdc34 (E2), and a putative F-box protein.

DNA damage also results in the activation of Chk1 kinase that phosphorylates the Cdc25C phosphatase on Ser-216. 14-3-3 protein binds to phosphorylated Cdc25C and sequesters this complex in the cytoplasm. Active Cdc25C is required to activate CyclinB/Cdk2 to allow $\mathrm{G}_{2}$-to-M transition. Thus, DNA damage also blocks cell cycle progression at the $\mathrm{G}_{2}$-to-M checkpoint. 
a common and critical mechanism for the selective destruction of signaling and cell cycle proteins by ubiquitin-mediated proteolysis (Craig and Tyers 1999; Tyers and Willems 1999|. This scheme was first established for a complex of proteins (termed SCF) that control S phase progression in Saccharomyces cerevisiae, through their ability to degrade their targets in a fashion that imposes order on the cell cycle (Willems et al. 1996; Skowyra et al. 1997; Patton et al. 1998). In yeast, a protein termed Cdc53 (corresponding to the cullins of multicellular organisms) serves as a scaffold to recruit an adaptor (Skp1), an E2 protein-ubiquitin ligase (Cdc34), and a ring finger protein (Rbxl), which potentiates substrate ubiquitination. Skp1 links the Cdc53 complex to one of many proteins with a conserved Skp1-binding domain, termed an F box. F-box proteins contain the eponymous $\mathrm{F}$ box at the amino terminus and a variable carboxyl terminus, typically comprised of WD40 repeats or leucine-rich repeats, which directly contacts the target for ubiquitination. In several cases, phosphorylation of the target is required for its association with the F-box protein. This has been nicely demonstrated for the yeast protein Sic1, which is the only essential target for Cdk activity during the $G_{1}$ phase of the cell cycle. Sicl is an inhibitor of the $G_{2} / M$ phase Cdk complex, and its inactivation by proteolytic degradation, is required for passage through the cell cycle. Sicl becomes phosphorylated at multiple serine residues and subsequently associates with the carboxyterminal WD40 repeats of an F-box protein termed Cdc4, resulting in its degradation. The targeting of specific proteins for degradation through their association with Fbox proteins likely regulates many events in signal transduction (Fig. 4). As an example, phosphorylated ІкB is recognized by $\beta \mathrm{TrCP}$, a mammalian $\mathrm{F}$-box protein with carboxy-terminal WD40 repeats, that is closely related to the yeast Cdc4 (Yaron et al. 1998; Winston et al. 1999). Thus a pivotal event in TNF-R signaling involves the phospho-dependent recognition of the IкB inhibitor by an F-box protein.

\section{Scaffolding and docking interactions in protein serine/threonine kinase pathways}

The data summarized above have indicated that the phosphorylation of serine/threonine residues directly regulates protein-protein interactions. Many of the signaling pathways that control serine/threonine phosphorylation are composed of a succession of protein kinases (MAPK cascades for example), raising the issue as to how specificity is preserved under such circumstances. Clearly, protein serine/threonine kinases preferentially phosphorylate specific motifs in their substrates, but the experience with tyrosine kinases suggests that they might have more extensive interactions with their targets. Indeed, two types of docking interactions appear important in determining specificity in pSer/Thr signaling. Protein kinases are often anchored to a scaffolding protein that may either facilitate the flow of information from one kinase to another, or hold the kinase in a latent state close to the receptor that will induce its activation (Pawson and Scott 1997; Whitmarsh and Davis 1998). Furthermore, MAPKs appear to have specific docking interactions with their immediate substrates and regulators that likely enhance the specificity of MAPK pathways (Holland and Cooper 1999) (Fig. 5).
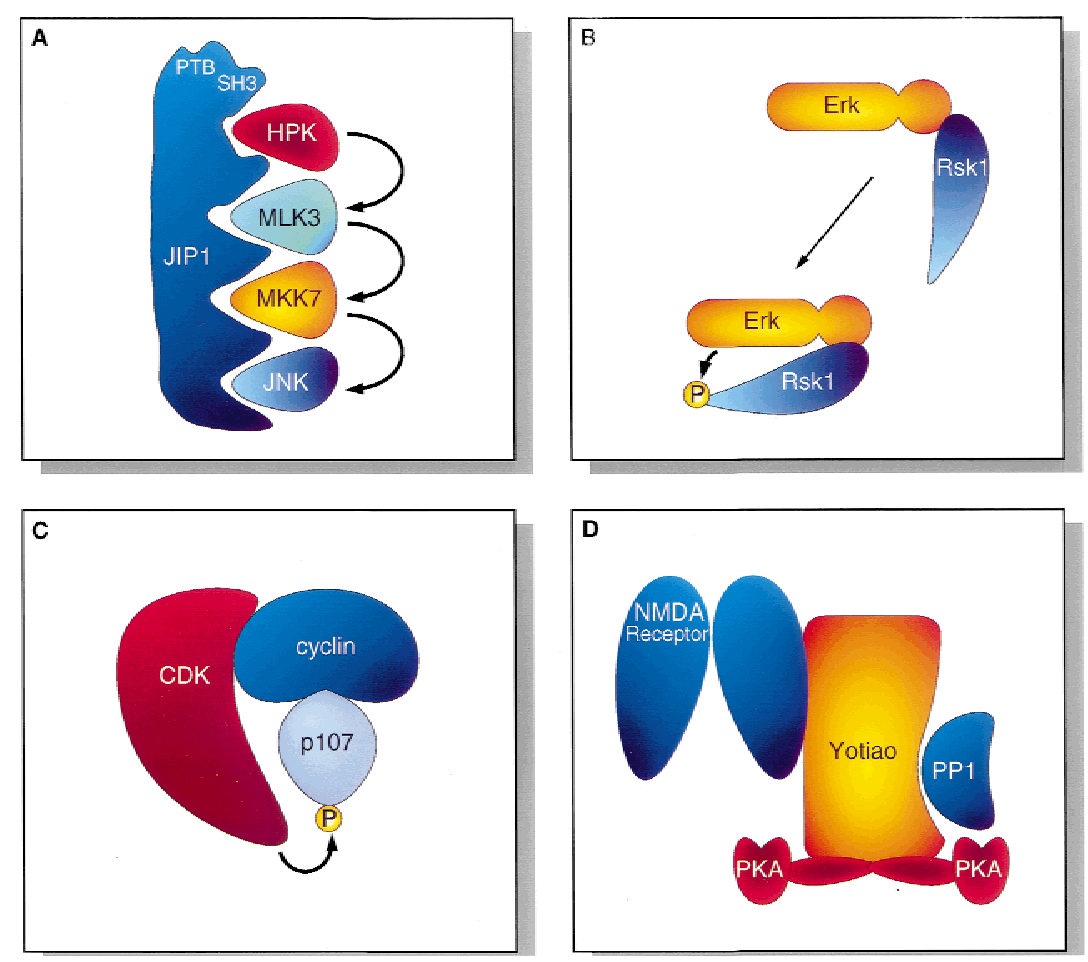

Figure 5. Scaffold mediated assembly of signaling pathways. (A) Jip1 acts as a scaffold for the mammalian Jnk MAPK cascade. Jip1 has separate binding sites for Jnk, and the upstream kinases MKK7 (MAPKK), MLK3 (MAPK), and HPK1. Jip1 also has SH3 and PTB domains that may tether the complex to additional proteins involved in upstream activation or localization. (B) The Erk MAPK docks to target proteins. Once tethered in this manner, Erk phosphorylates the substrate, Rsk1. (C) The regulatory cyclin A subunit of Cdk2 binds substrates with a conserved RXL motif, such as p107. (D) The AKAP protein Yotiao binds to the NMDA receptor, PKA in the inactive form, and PP1 in the active form. In doing so, Yotiao creates close physical association of the components that repress resting NMDA receptor and enhance channel activation. 
The classical example of this latter type of scaffolding protein is the Ste5 polypeptide in yeast, which is required for growth arrest and mating, and acts downstream of the G-protein coupled pheromone receptor to regulate a MAPK cascade (Elion 1998). Ste5 interacts with the G $\beta$ subunit (Ste4) (Pryciak and Huntress 1998), and has independent binding sites for a MAPKKK (Ste11), a MAPKK (Ste7), and a MAPK (Fus3) (Choi et al. 1994). Various functions have been proposed for Ste5, notably to increase the fidelity of the pathway by physically juxtaposing successive kinases, to localize these kinases to specific subcellular compartments, and to insulate interacting kinases from separate pathways. It is also possible that Ste5 oligomerization could enhance kinase activation by promoting intermolecular autophosphorylation. The potential importance of scaffolding proteins is underscored by the observation that the MAPKKK Ste11 also acts in the yeast osmosensing pathway, although the other components of the pathway, including the Hog 1 MAPK are different. In this case, the MAPKK Pbs2 provides the scaffolding function through an extended amino terminus. Pbs 2 engages both Ste 11 and Hog1, as well as the osmosensing receptor (Shol), which has an SH3 domain that binds a proline-rich motif in Pbs2 (Posas and Saito 1997). Thus, Pbs2 serves a somewhat analagous function to Ste 5 in assembling the elements of a signaling pathway into an individual complex.

Recent data suggest that scaffolding proteins akin to Ste5, likely play an important role in organizing MAPKs in mammalian cells. In particular, several proteins have been identified that bind members of the Jnk MAPK pathway and potentiate Jnk activation (Yasuda et al. 1999; Kelkar et al. 2000). JIP1 and JIP2 are closely related proteins that have separate binding sites for Jnk, and the upstream kinases MKK7 (a MAPKK), MLK3 (a MAPKKK), and HPK1, a Ste20-related kinase that activates MLK3 (Fig. 5A). JIP1/2 appear to be activators of Jnk signaling, and can form large cytoplasmic complexes through their ability to make homo- or hetero-oligomers. They are relatively selective for specific members of the Jnk signaling cassette, suggesting that they serve both to enhance activation and to impose specificity. Interestingly, these JIP proteins have carboxy-terminal SH3 and PTB domains, which might aid in their localization, or association with other signaling proteins. Indeed the JIP-1 PTB domain binds a RhoGEF, and JIP-1 is localized to the tips of neurites in cultured neuronal cells (Meyer et al. 1999).

In addition to the indirect association of MAPKs and their upstream regulators, mediated by their common interaction with the same scaffolding protein, MAPKs can bind directly to their substrates and regulators through noncatalytic docking sites. Like other protein kinases, the Erk and Jnk MAPKs preferentially phosphorylate serine or threonine in a specific consensus sequence, minimally Ser/Thr-Pro. However, this does not fully explain the specificity of MAPK substrate selection in vivo. Rather, it appears that physiological substrates for MAPKs have separate motifs that tether the enzyme to its phosphorylation target. A common docking site for the Erk MAPK is formed by a short stretch of basic resi- dues, found in substrates such as the protein kinases Rsk1/2 and Mnk2, and markedly increases the efficiency with which they are phosphorylated (Waskiewicz et al. 1997; Gavin and Nebreda 1999). The docking motif binds a negatively charged region carboxy-terminal to the Erk catalytic domain. Remarkably, the same basic motif is found in a kinase (Mek) and phosphatase (MKP) that respectively phosphorylate and dephosphorylate Erk, suggesting that substrates and regulators may compete for the same binding site on the Erk protein kinase (Tanoue et al. 2000). A similar common docking (CD) domain is found in the Jnk and p38 MAPK family members, and also appears to specify interactions with substrates and regulators. A distinct docking site (FXFP) is found in Erk substrates such as the Elk-1 transcription factor, and its presence markedly enhances the affinity with which the kinase and substrate interact, resulting in enhanced phosphorylation (Jacobs et al. 1999). Elk-1 has an additional docking motif, the D box, that binds both to Erk and Jnk, and is related to the $\delta$ domain in c-Jun that confers high affinity binding to Jnk. Interestingly, these motifs are portable, in the sense that they will convert a poor target into a high affinity substrate for the relevant MAPK, and act in synergy to enhance phosphorylation.

Results of this type have suggested that MAPKs, and possibly many other serine/threonine kinases, select their substrates first through a noncatalytic docking interaction, which determines the substrate to be phosphorylated. This is followed by the recognition of a specific site within the bound protein for phosphorylation at the enzyme's active site (Fig. 5B). Indeed the regulatory cyclin A subunit of Cdk2 binds substrates with a conserved RXL motif, such as p107, in a fashion that is important for their subsequent phosphorylation (Schulman et al. 1998) (Fig. 5C). In a related vein, specific cyclins in yeast (Pcl8/Pcl10) direct the Pho85 Cdk to phosphorylate glycogen synthase and thereby antagonize glycogen accumulation (Huang et al. 1998). In principle, these mechanisms through which protein serine/threonine kinases increase the local concentration of their physiological substrates is very similar to the devices by which tyrosine kinases attract their targets. Thus, it appears that docking interactions of this sort may be a very general phenomenon in the recognition of protein kinase substrates and therefore in determining the specificity of signal transduction.

The ability of scaffolding proteins to organize the protein kinases and phosphatases that regulate serine/ threonine phosphorylation is typified by the A kinase anchoring proteins (AKAPs) (Colledge and Scott 1999). These represent a growing family of large polypeptides, that contain binding sites for various protein serine/ threonine kinases and phosphatases, as well as a targeting motif that directs the resulting complex to a specific site in the cell. PKA has a catalytic subunit (C) whose activity is repressed by binding to a regulatory (R) subunit. Receptors such as GPCRs elevate the level of cAMP, which binds to the R subunit and induces dissociation of a free $\mathrm{C}$ subunit. In addition to its CAMPbinding sites, the $\mathrm{R}$ subunits have an amino-terminal 
domain required for dimerization and binding to the AKAP. In the case of the RII subunit, the dimerized amino terminus forms a four-helix bundle that creates a groove to accommodate an amphipathic $\alpha$-helix from the AKAP (Newlon et al. 1999). Thus a short motif on the AKAP binds the RII subunit of PKA, holding the kinase in an inactive state at a subcellular site dictated by the AKAP. AKAPs bind not only to PKA, but also to other protein kinases such as PKC isoforms, as well as serine/ threonine phosphatases (PPI and PPII). In general, the AKAPs appear to anchor the kinases and phosphatases in an inactive state, close to their activators and substrates. Yotiao is a $\sim 210-\mathrm{kD}$ protein that interacts directly with the NR1A subunit of the NMDA receptor and binds both the RII subunit of PKA in an inactive state, as well as the phosphatase PP1 in an active form (Westphal et al. 1999). NMDA receptor channel activity is positively regulated by phosphorylation, and by physically linking a constitutively active phosphatase to NR1A, Yotiao appears to repress the activity of the channel under resting conditions. However, the simultaneous juxtaposition of inactive PKA with the receptor means that Yatiao also enhances channel activation once cAMP liberates an active C subunit, overcoming the inhibitory activity of the phosphatase (Fig. 5D). Thus protein-protein interactions appear to be an important determinant of specificity in signaling by neurotransmitter receptors. This theme that has been echoed by the discovery of a complex network of interacting proteins in the post-synaptic density, that largely through PDZ domain-mediated interactions appears to organize the localization and signaling activities of glutamate receptors and GPCRs (Fanning and Anderson 1999; Tu et al. 1999).

\section{Guidance receptors and signaling to the cytoskeleton}

It is common when considering signaling pathways to dwell on events that culminate in the nucleus. However, signaling pathways that control the cytoskeleton and adhesion of cells to the extracellular matrix are essential for guided cell migration, including processes such as axon guidance and topographic map formation in the brain. Recent work has identified a number of cell surface receptors that mediate the responses of axons to both repulsive and attractive cues, and which play a larger role in the guided movement of multiple cell types (Tessier-Lavigne and Goodman 1996). Among these guidance receptors are members of the Eph family of RTKs. Mammalian Eph receptors interact with ligands, termed ephrins, which are themselves anchored to the cell surface, either through a GPI linkage (A-type ephrins) or a transmembrane sequence joined to a conserved cytoplasmic tail (B-type ephrins) (Holder and Klein 1999). Physiological Eph receptor activation apparently requires a direct interaction between receptor and ephrin-expressing cells. Upon activation, Eph receptors undergo autophosphorylation at multiple sites, including the kinase domain activation loop and at tyrosine residues within a conserved motif in the juxtamembrane region (Kalo and Pasquale 1999). Surprisingly, the juxta- membrane autophosphorylation sites appear to have a dual function since they contribute to receptor kinase activation, as well as providing docking sites for proteins with SH2 domains (Holland et al. 1997; Binns et al. 2000; Zisch et al. 2000). In addition to binding SH2 proteins directly, Eph receptors can phosphorylate docking proteins such as p62 dok, which engages Ras GAP and the SH2/SH3 adaptor Nck through SH2-mediate interactions (Holland et al. 1997).

Eph receptors have many functions in vertebrates and invertebrates, including regulation of angiogenesis, the formation of boundaries between rhombomeres, formation of the palate, and tissue morphogenesis. However, they have been most intensively studied for their role in axon guidance and topographic map formation in the central nervous system (Flanagan and Vanderhaeghen 1998). The binding of ephrins to neuronal cells expressing Eph receptors induces remodeling of the actin cytoskeleton and growth cone collapse, in a fashion that is dependent on receptor kinase activity and the juxtamembrane pTyr sites (Drescher et al. 1995; Binns et al. 2000). These data suggest that activated Eph receptors can communicate with signaling proteins that regulate the cytoskeleton. There are a number of candidates that might fulfil this role, including the Nck adaptor.

Nck has a carboxy-terminal $\mathrm{SH} 2$ domain that binds pTyr sites, and three amino-terminal SH3 domains that engage a variety of proteins implicated in cytoskeletal organization (Buday 1999). In particular, the second SH3 domain of Nck binds the protein serine/threonine kinase Pak (Bokoch et al. 1996; Lu et al. 1997) (Fig. 6). Pak has a carboxy-terminal kinase domain, and an extended amino terminus that binds the SH3 domains of both Nck and a Rac/Cdc42 GEF termed PIX (Manser et al. 1998), as well as recognizing GTP-bound Rac/Cdc42 GTPases. Nck recruits Pak to the membrane, whereas binding of Cdc42 appears to directly increase Pak kinase activity,

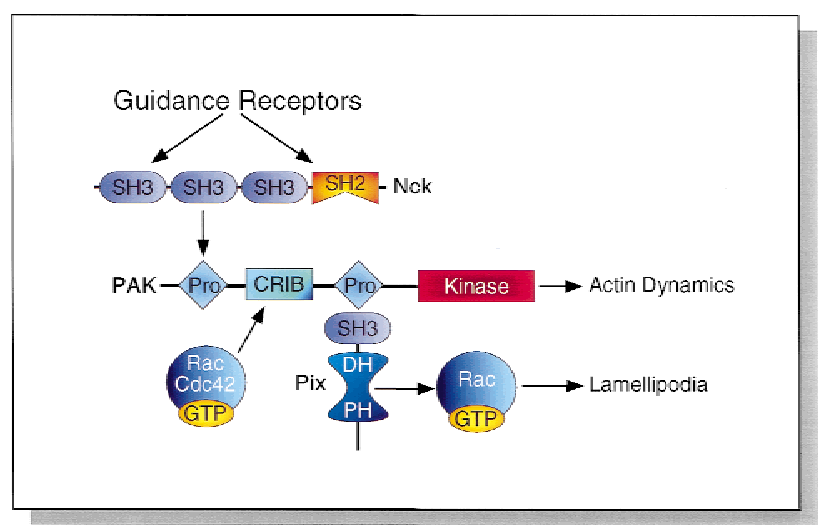

Figure 6. A signaling pathway to the cytoskeleton. Axon guidance receptors potentially bind the Nck adaptor, through both SH2-and SH3-mediated interactions. The second SH3 domain of Nck recruits the Pak protein serine/threonine kinase to the membrane. Pak kinase activity is induced by binding of GTPCdc42 to a CRIB motif. Pak can also generate activated Cdc42 through the associated PIX GEF. (Pro, proline-rich motif). 
likely by causing a conformational change that releases an inhibitory effect of the amino terminus. Thus, Pak may have two ways to modify the actin cytoskeleton. One being a kinase-dependent effect through phosphorylation of substrates such as myosin light-chain kinase (Sanders et al. 1999), whereas the interaction with PIX can deliver a kinase-independent signal through Cdc42/ Rac activation (Fig. 6).

Genetic data from Drosophila support the idea that Nck and Pak are important for the control of axon guidance. Mutations in the Drosophila Nck homolog (termed Dreadlocks or Dock) cause striking defects in the guidance and targeting of photoreceptor axons, and this aberrant behavior is mimicked by mutations in Drosophila Pak (Hing et al. 1999). Interestingly, mutations in both the Cdc42- and Nck-binding sites impair the ability of Pak to steer axons correctly. Such data have suggested that modular proteins of the sort identified in other signaling pathways play important roles in linking cell surface receptors to the actin cytoskeleton, and thus to the control of guided cell movement. Indeed there are an increasing number of such examples.

Two signaling proteins appear central to controlling the cytoskeleton and may serve as convergence points downstream from a variety of guidance receptors (Fig. 7). The Drosophila Enabled (Ena) protein, and its mammalian homolog Mena, are stongly implicated in regulating actin dynamics (Lanier and Gertler 2000). Mena has an

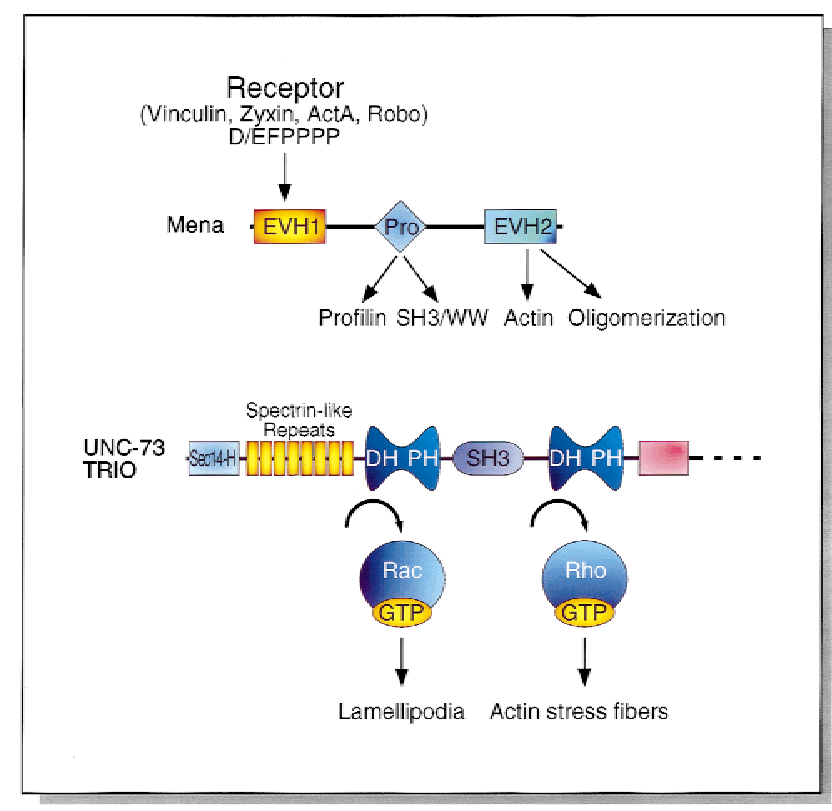

Figure 7. Modular proteins that may integrate cytoskeletal signaling. Mena interacts with receptors, focal adhesion components, and bacterial pathogens through its EVH1 domain, and has multiple motifs that potentially couple to the actin cytoskeleton. UNC-73/Trio has an amino-terminal domain related to yeast Sec 14, multiple spectrin repeats, and two DH-PH domains that activate Rac and Rho respectively. The signaling pathways that lie upstream of UNC-73/Trio are not well established. amino-terminal EVH1 domain that interacts with proteins found in focal complexes, such as vinculin and zyxin, with the ActA protein of the bacterial pathogen Listeria monocytogenes, and the guidance receptor Roundabout (Robo) (Gertler et al. 1996; Prehoda et al. 1999). The central region of Mena has proline-rich motifs that associate with the actin/phospholipid-binding protein profilin, and with proteins that possess SH3 or WW domains. At its carboxyl terminus, Mena has an EVH2 domain involved in dimerization and association with actin. Thus Mena can potentially link proteins with E/DFPPPP motifs that bind the EVH1 domain to regulation of the actin cytoskeleton (Lanier et al. 1999). Another multi-domain protein that acts in neurons to control axon guidance is UNC-73 (Steven et al. 1998), the C. elegans counterpart of mammalian Trio (Debant et al. 1996). Whereas UNC-73 and Trio differ at their extreme carboxyl termini, they both have an amino-terminal domain found in proteins such as yeast Sec14, that bind phosphatidylinositol, followed by multiple spectrin repeats and a DH-PH domain that serves as a GEF for the Rac GTPase. This region is connected by an SH3 domain to a second DH-PH domain that has Rho GEF activity. The structure of UNC-73/Trio suggests that it may couple signals to the regulation of Rho family GTPases and thus to reorganization of the cytoskeleton. Indeed, loss-of-function mutations in unc-73 cause a variety of defects in guided cell movements, and a substitution in the first DH domain that inhibits its Rac GEF activity disrupts axon guidance (Fig. 7). A challenge for the future will be to sort out how cell surface guidance receptors communicate with cytoplasmic signaling molecules such as Mena and Unc-73/Trio. Some clues can be gained by considering a series of new guidance receptors whose connections to intracellular pathways are currently mysterious.

The Robol receptor in Drosophila binds the mid-line repellant Slit and therefore prevents axons from crossing (or recrossing) the midline (Kidd et al. 1998, 1999; Brose et al. 1999). The cytoplasmic region of Robo has a number of proline-rich motifs that are conserved in evolution, and as noted above can potentially interact with the Mena EVH1 domain as well as with SH3-containing proteins. Thus, it seems likely that Robo affects the cytoskeleton through modular proteins with the capacity to bind specific proline-rich sequences.

The UNC-5 protein, conserved from C. elegans to mammals, responds to the extracellular ligand netrin and has a repulsive effect on the growth cone (LeuingHagesteijn et al. 1992; Leonardo et al. 1997), commonly in association with a quite different netrin-receptor, UNC-40/DCC (Chan et al. 1996). Remarkably, netrin has an attractive effect on axons that only express UNC40/DCC, which is converted into a repulsive effect upon expression of UNC-5 and its association with UNC-40/ DCC (Hong et al. 1999). The mechanisms by which UNC-5 and UNC-40 signal are currently unknown, but their cytoplasmic regions appear to have a modular construction. UNC-5 has a carboxy-terminal death domain, although this seams dispensable for axon guidance, and a 
central region also found in the cell junction protein ZO-1 and the cytoskeletal protein ankyrin. Furthermore, UNC-5 and UNC-40/DCC interact directly with one another through their cytoplasmic regions. The finding that guidance receptors exert quite different effects depending on their association with a coreceptor or following elevation of cAMP or cGMP (Song et al. 1998), adds a fascinating complexity that has yet to be explored at the biochemical level. Similar to UNC-5, the plexins, which act as receptors for the semaphorin guidance molecules, have conserved cytoplasmic domains whose biochemical activities are unknown (Tamagnone et al. 1999). Elucidating the signaling pathways activated by these diverse guidance receptors will be important for understanding the complexities of cell movement, and the formation of complex tissues such as the brain.

\section{Integration of signaling pathways}

In the body, a cell will be simultaneously exposed to multiple, potentially contradictory signals, in the form of soluble hormones and ligands anchored to adjacent cells or the ECM. The cell must have mechanisms for converting these various signals into a defined response. Furthermore, the cell must monitor its internal state so that it does not attempt to divide before achieving the appropriate mass, for example. There are some clues as to how these types of regulation may be achieved. In one mode of integration, activation of a key signaling protein requires input from two or more distinct biochemical pathways. The Rsk1 protein serine/threonine kinases exhibits such behavior. Rsk1 has two catalytic domains, of which the amino-terminal domain phosphorylates downstream targets. The amino-terminal kinase domain is controlled by multiple inputs, including the carboxyterminal domain. The Erk MAPK binds a basic docking site at the extreme carboxyl terminus of Rsk1, and phosphorylates sites in the linker region between the two kinase domains and in the carboxy-terminal domain, which are essential for activation. Full activation, however, also requires phosphorylation of the amino-terminal kinase domain by the $\mathrm{PIP}_{3}$-responsive protein kinase PDK1 (Nebreda and Gavin 1999; Richards et al. 1999). Rsk1 activation, therefore, requires inputs from both the Erk MAPK pathway and the PI3K pathway (Fig. 8A).

Clearly much of the integration of signaling pathways occurs at the level of transcriptional promoters. Thus the transcription factors regulated by the TGF $\beta$ and Wnt signaling pathways (Smads and $\beta$-catenin complexed with Lef1/Tcf, respectively) can physically interact with one another and synergistically activate gene expression during embryonic development (Nishita et al. 2000).

An alternative scenario is that two different pathways have opposing effects, and the cell may therefore want to prevent their simultaneous activation. A process of this sort is seen for signaling with the interferon- $\gamma$ receptor which, through activation of the Stat 3 transcription factor, induces expression of Smad7 (Ulloa et al. 1999). Smad7 inhibits TGF $\beta$ receptor signaling since it binds the activated receptor but lacks phosphorylation sites and does not engage the common Smad4. Thus, cytokine signaling not only activates a specific cellular response, it also impairs the cell's ability to respond to a conflicting signal (Fig. 8B). A related effect has been proposed for the Erk MAPK pathway, since Erk phosphorylates Smad2/3 in the linker region between the MH1 and $\mathrm{MH} 2$ domains, thereby apparently poisoning Smad re-

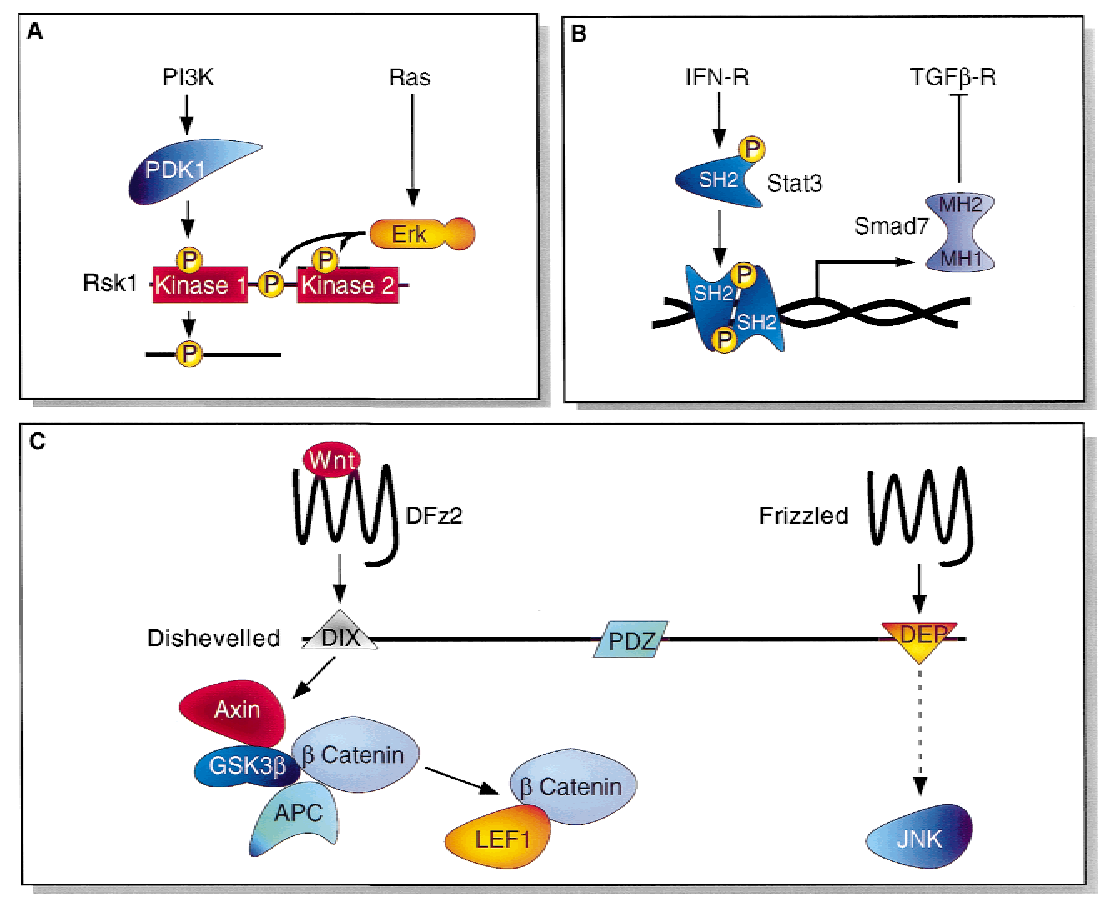

Figure 8. Integration of signaling pathways. (A) Activation of Rsk1 requires phosphorylation by both PDK1 and ERK MAPK. Thus the PI3K and Ras pathways synergize to stimulate the Rsk1 protein serine/threonine kinase. $(B)$ Signaling through the interferon (IFN) $\gamma$ receptor-Stat3 pathway induces the expression of the inhibitory Smad7, which blocks the activity of the TGF $\beta$ receptor. Thus one cytokine pathway inhibits the activation of a distinct pathway. $(C)$ Both the Wnt receptor (DFz2) and the related Frizzled signal through the multidomain protein Dishevelled. Wnt signaling involves the DIX and PDZ domains of Dishevelled, which activate the $\beta$-catenin pathway. Frizzled signals through the carboxy-terminal DEP domain to activate the JNK MAPK pathway. 
tention in the nucleus and blocking TGF $\beta$ signaling (Kretzschmar et al. 1999).

An additional twist is that an individual signaling protein may regulate signaling through multiple distinct pathways, as appears to be the case for the modular cytoplasmic protein Dishevelled (Dsh) (Cadigan and Nusse 1996). Dsh has an amino-terminal DIX domain, which it shares with the protein axin, a central PDZ domain, and a carboxy-terminal DEP domain, a module found in a variety of signaling proteins, notably proteins involved in regulating $G$ protein signaling, but currently of unknown function. Dsh plays a key role in signaling from Wnt receptors (such as DFz2 in Drosophila) to a complex composed of axin/conductin, the GSK3 $\beta$ protein kinase, $\beta$-catenin and APC (Zeng et al. 1997; Behrens et al. 1998; Fagotto et al. 1999). This activity of Dsh requires the amino-terminal DIX and PDZ domains and likely involves a direct interaction with the DIX domain of axin (Itoh et al. 2000). In the absence of Wnt signaling, phosphorylation of $\beta$-catenin by GSK3 $\beta$ creates recognition sites for the F-box protein $\beta \operatorname{TrCP}$, leading to $\beta$-catenin ubiquitination and degradation (Hart et al. 1999). Following Wnt stimulation, Dsh inhibits $\beta$-catenin phosphorylation, possibly by displacing GSK $3 \beta$ from the complex, and the accumulating $\beta$-catenin moves to the nucleus where it activates gene expression in a complex with the Lef1/Tcf transcription factor (Behrens et al. 1996). Dsh, however, has a completely different role downstream of the Drosophila Frizzled receptor, which controls epithelial planar polarity. This signaling pathway is mediated by its carboxy-terminal DEP domain, which leads to the activation of the Jnk pathway (Boutros et al. 1998) (Fig. $8 \mathrm{C})$.

\section{Evolution of signaling pathways}

One might wonder why the cell has made such extensive use of modular domains and portable recognition motifs to organize signal transduction. A likely explanation is that this allows for the rapid evolution of new signaling pathways, through the simple device of joining existing domains together in novel combinations, and by allowing variations in binding interfaces to generate new specificities. As an example, once the cell has generated an SH2 domain with the ability to recognize a pTyr motif, as apparently happened very early in the evolution of multicellular animals (Kawata et al. 1997), the cell has a portable module that can be duplicated and inserted into pre-existing enzymes or adaptors to render them responsive to tyrosine kinase signaling. Simple mutation could then generate SH2 domains with new recognition properties (as can be achieved in vitro), allowing receptors to interact selectively with a subset of cytoplasmic targets. Although yeast have no conventional tyrosine kinases and no functional SH2 domains, they nonetheless have many protein modules, $\mathrm{SH} 3$ and $\mathrm{EH}$ domains among others, which regulate events such as endocytosis, vesicle trafficking, and cytoskeletal organization (Tang et al. 2000). The subsequent appearance of SH2 domains has apparently allowed the cell to join this freshly minted module to pre-existing SH3 domains, thereby creating new adaptor proteins that couples pTyr signaling to targets with proline-rich SH3-binding motifs. The reiterated use of a limited number of protein modules also allows for the evolution of networks of interacting pathways and the targeting of signaling complexes to specific subcellular sites.

This approach to the design of signaling pathways has its own potential difficulties. Signaling events must organize the entire complex behavior of the cell, and this must be achieved through an apparently small number of core signaling pathways, built on a restricted group of protein modules. This immediately suggests that interaction domains and signaling pathways must have multiple biological functions. Thus although PTB, PDZ, and SH3 domains, as an example, play important roles in tyrosine kinase signaling, they are also essential for quite different processes such as the establishment of cell polarity and asymmetric cell division. During development, cells must frequently divide in an asymmetric fashion, such that the two daughter cells are inherently different from one another, both to establish polarized tissues and to allow a single stem cell to generate several distinct mature cell types. Commonly this is achieved through regulatory proteins that themselves become asymmetrically localized during mitosis and are preferentially delivered into one of the resulting cells, where they organize its polarity and fate. Work in C. elegans, Drosophila, and mammals has established that a protein termed PAR-3 (Bazooka in flies and ASIP/PHIP in vertebrates) plays an organizing role in such processes (Etemad-Moghadam et al. 1995; Tabuse et al. 1998; Lin et al. 1999; Schober et al. 1999; Wodarz et al. 1999). PAR-3 has three PDZ domains and a carboxy-terminal region that interacts with the atypical PKC isoforms, and may therefore serve a scaffolding function in establishing cellular asymmetry. In a Drosophila stem cell, the sensory organ precursor cell, PAR-3/Bazooka is genetically upstream of other modular proteins, including Numb (Rhyu et al. 1994). Numb has an amino-terminal PTB domain, which unlike the PTB domains of She and IRS-1, does not require pTyr for peptide recognition and is rather flexible in its binding properties (Li et al. 1998), and specifies a neuronal cell fate by inhibiting signaling through the Notch pathway (Frise et al. 1996). Data of this sort has established that asymmetric cell division, accomplished in response to intrinsic cues, is controlled by modular proteins with interaction domains very similar to those used in signaling pathways that respond to external stimuli. Thus the cell has in part solved the issue of complexity by using subtle variants of the same domains to regulate a wide array of intracellular processes.

\section{Regulating the intensity of signaling pathways}

One way in which the cell could use the same signaling pathways to control a wide range of cellular processes is to vary the amplitude and duration with which a pathway is activated, and to convert this into qualitatively different biological responses. Consistent with this pos- 
sibility, the cell apparently devotes considerable effort to producing proteins that act as regulators of signaling pathways. These may act simply to terminate signaling, but may also have more specific effects on downstream signaling. One recent example, which also illustrates the versatility of interaction modules, involves the product of the human disease gene SH2D1A, termed SAP (Sayos et al. 1998). Mutations in SH2D1A cause an unusual immunodeficiency resulting from an inability to control the effects of Epstein-Barr virus (EBV) infection (Klein and Klein 1998). The SAP protein is comprised of a single SH2 domain with only a few flanking residues, which binds costimulatory receptors in T cells, called SLAM and 2B4. Unlike all other SH2 domains, SAP recognizes not only phosphotyrosine in the context of carboxy-terminal residues, but also engages three residues aminoterminal to the pTyr (Li et al. 1999; Poy et al. 1999). As a consequence, SAP can bind with relatively high affinity to unphosphorylated Tyr-based motifs, although the affinity increases about fivefold upon ligand phosphorylation. These data suggest that SAP may modulate signaling by other $\mathrm{SH} 2$ proteins, either by occupying a potential phosphorylation and blocking its modification or by binding with very high affinity to the phosphorylated site and preventing access to SH2 signaling proteins, such as the Shp2 tyrosine phosphatase. SAP does not appear to play a central role in $\mathrm{T}$ cell development or function; however, in its absence EBV-infected B cells elicit an inappropriate response in cytotoxic $\mathrm{T}$ lymphocytes. Thus, although the effect of SAP on T cell function is subtle, it is of sufficient importance to be required for the survival of individuals infected with EBV.

In a similar vein, tyrosine kinases recruit a variety of inhibitory SH2 proteins. These include the E3 proteinubiquitin ligase c-Cbl, and members of Cis/SOCS family of regulators. Expression of SOCS proteins is induced by Stat-mediated cytokine signaling, and they in turn bind cytokine receptors and associated JAK tyrosine kinases and repress signal transduction (Starr et al. 1997; Starr and Hilton 1999). At their carboxyl terminus, they possess a domain termed the SOCS box, with motifs that bind the protein elongin B and C. The SOCS box may be analagous to the F-box domain discussed above, while elongin C is related to the Skpl adaptor of the SCF complex. SOCS proteins may therefore form complexes similar to SCF that target associated polypeptides for destruction (Zhang et al. 1999). We have touched here on a few of the regulators of tyrosine kinase signaling, but it is evident that similar controls influence signaling through other pathways (Zeng et al. 2000).

\section{Conclusions}

The completion of genome sequences yields the entire set of proteins that an organism can make. As we understand more about the mechanisms through which signaling pathways are assembled, and the molecular infrastructure that organizes cellular behavior, we can contemplate defining the full wiring diagram of the cell, and employing this information in the treatment of the many diseases that result from breakdowns in the signaling process.

\section{Acknowledgments}

We thank Gerald Gish for preparing Figure 1. Work in the authors' laboratory is supported by the Medical Research Council (MRC) of Canada, the National Cancer Institute of Canada, and the Ontario R\&D Challenge Fund. P.N. receives a postdoctoral fellowship from the MRC, and T.P. is a Distinguished Scientist of the MRC and an International Research Scholar of the Howard Hughes Medical Institute.

\section{References}

Aghazadeh, B. and M.K. Rosen. 1999. Ligand recognition by SH3 and WW domains: The role of N-alkylation in PPII helices. Chem. Biol. 6: R241-R246.

Alessi, D.R., M. Deak, A. Casamayor, F.B. Caudwell, N. Morrice, D.G. Norman, P. Gaffney, C.B. Reese, C.N. MacDougall, D. Harbison, A. Ashworth, and M. Bownes. 1997. 3-phosphoinositide-dependent protein kinase-1 (PDK1): Structural and functional homology with the Drosophila DSTPK61 kinase. Curr. Biol. 7: 776-789.

Andjelkovic, M., S.M. Maira, P. Cron, P.J. Parker, and B.A. Hemmings. 1999. Domain swapping used to investigate the mechanism of protein kinase B regulation by 3-phosphoinositide-dependent protein kinase 1 and Ser473 kinase. Mol. Cell. Biol. 19: 5061-5062.

Arch, R.H., R.W. Gedrich, and C.B. Thompson. 1998. Tumor necrosis factor receptor-associated factors (TRAFs) - family of adapter proteins that regulates life and death. Genes \& Dev. 12: 2821-2830.

Ashkenazi, A. and V.M. Dixit. 1998. Death receptors: Signaling and modulation. Science 281: 1305-1308.

Behrens, J., J.P. von Kries, M. Kuhl, L. Bruhn, D. Wedlich, R. Grosschedl, and W. Birchmeier. 1996. Functional interaction of $\beta$-catenin with the transcription factor LEF-1. Nature 382: 638-642.

Behrens, J., B.A. Jerchov, M. Wurtele, J. Grimm, C. Asbrand, R. Wirtz, M. Kuhl, D. Wedlich, and W. Birchmeier. 1998. Functional interaction of an axin homolog, conductin, with $\beta$-catenin, APC, and GSK3 $\beta$. Science 280: 596-599.

Belham, C., S. Wu, and J. Avruch. 1999. Intracellular signalling: PDK1-a kinase at the hub of things. Curr. Biol. 9: R93-R96.

Bell, D.W., J.M. Varley, T.E. Szydlo, D.H. Kang, D.C. Wahrer, K.E. Shannon, M. Lubratovich, S.J. Verselis, K.J. Isselbacher, J.F. Fraumeni, J.M. Birch, F.P. Li, J.E. Garber, and D.A. Haber. 1999. Heterozygous germ line hCHK2 mutations in Li-Fraumeni syndrome. Science 286: 2528-2531.

Binns, K., P.P. Taylor, F. Sicheri, T. Pawson, and S.J. Holland. 2000. Phosphorylation of tyrosine residues in the kinase domain and juxtamembrane region regulates the biological and catalytic activities of Eph receptors. Mol. Cell. Biol. (in press).

Blume-Jensen, P., G. Jiang, R. Hyman, K.F. Lee, S. O'Gorman, and T. Hunter. 2000. Kit/stem cell factor receptor-induced activation of phosphatidylinositol 3 '-kinase is essential for male fertility. Nat. Genet. 24: 157-162.

Bokoch, G.M., Y. Wang, B.P. Bohl, M.A. Sells, L.A. Quilliam, and U.G. Knaus. 1996. Interaction of the Nck adapter with p21-activated kinase (PAK1). I. Biol. Chem. 271: 2574625749.

Borg, J.P., J. Ooi, E. Levy, and B. Margolis. 1998. The phospho- 
tyrosine interaction domains of X11 and FE65 bind to distinct sites on the YENPTY motif of amyloid precursor protein. Mol. Cell. Biol. 16: 6229-6241.

Boutros, M., N. Paricio, D.I. Strutt, and M. Mlodzik. 1998. Dishevelled activates JNK and discriminates between JNK pathways in planar polarity and wingless signaling. Cell 94: 109-118.

Brose, K., K.S. Bland, K.H. Wang, D. Arnott, W. Henzel, C.S. Goodman, M. Tessier-Lavigne, and T. Kidd. 1999. Slit proteins bind Robo receptors and have an evolutionarily conserved role in repulsive axon guidance. Cell 96: 795-806.

Brunet, A., A. Bonni, M.J. Zigmond, M.Z. Lin, P. Juo, L.S. Hu, M.J. Anderson, K.C. Arden, J. Blenis, and M.E. Greenberg. 1999. Akt promotes cell survival by phosphorylating and inhibiting a forkhead transcription factor. Cell 96: 857-868.

Bubeck Wardenburg, J., R. Pappu, J.Y. Bu, B. Mayer, J. Chernoff, D. Straus, and A.C. Chan. 1998. Regulation of PAK activation and the $\mathrm{T}$ cell cytoskeleton by the linker protein SLP76. Immunity 9: 607-616.

Buday, L. 1999. Membrane-targeting of signalling molecules by $\mathrm{SH} 2 / \mathrm{SH} 3$ domain-containing adaptor proteins. Biochem. Biophys. Acta 1422: 187-204.

Chan, S.S., H. Zheng, M.W. Su, R. Wilk, M.T. Killen, E.M. Hedgecock, and J.G. Culotti. 1996. UNC-40, a C. elegans homolog of DCC (Deleted in Colorectal Cancer), is required in motile cells responding to UNC-6 netrin cues. Cell 87: 187-195.

Cadigan, K.M. and R. Nusse. 1996. wingless signaling in the Drosophila eye and embryonic epidermis. Development 122: 2801-2812.

Chen, X., U. Vinkemeier, Y. Zhao, D. Jeruzalmei, J.E. Darnell, Jr., and J. Kuriyan. 1998. Crystal structure of tyrosine phosphorylated STAT-1 dimer bound to DNA. Cell 93: 827-839.

Chinnaiyan, A.M., K. O'Rourke, M. Tewari, and V.M. Dixit. 1995. FADD a novel death domain-containing protein, interacts with the death domain of Fas and initiates apoptosis. Cell 81: 505-512.

Choi, K.Y., B. Satterberg, D.M. Lyons, and E.A. Elion. 1994. Ste5 tethers multiple protein kinases in the MAP kinase cascade required for mating in $S$. cerevisiae. Cell 78: 499-512.

Colledge, M.S. and J.D. Scott. 1999. AKAPs: From structure to function. Trends Cell Biol. 9: 216-221.

Craig, K.L. and M. Tyers. 1999. The F-box: A new motif for ubiquitin dependent proteolysis in cell cycle regulation and signal transduction. Prog. Biophys. Molec. Biol. 72: 299-328.

Cunningham, B.C. and J.A. Wells. 1991. Rational design of receptor specific variants of human growth hormone. Proc. Natl. Acad. Sci. 88: 3407-3411.

Darnell, J.E., Jr. 1997. STATs and gene regulation. Science 277: 1630-1635

Debant, A., C. Serra-Pages, K. Seipel, S. O’Brien, M. Tang, S.H. Park, and M. Streuli. 1996. The multi-domain protein Trio binds the LAR transmembrane tyrosine phosphatase, contains a protein kinase domain, and has separate rac-specific and rho-specific guanine nucleotide exchange factor domains. Proc. Natl. Acad. Sci. 93: 5466-5471.

Drescher, U., C. Kremoser, C. Handwerker, J. Löschinger, M. Noda, and F. Bonhoeffer. 1995. In vitro guidance of retinal ganglion cell axons by RAGS, a $25 \mathrm{kDa}$ tectal protein related to ligands for Eph receptor tyrosine kinases. Cell 82: 359370 .

$\mathrm{Du}, \mathrm{K}$. and M. Montminy. 1998. CREB is a regulatory target for the protein kinase Akt/PKB. J. Biol. Chem. 273:3237732379.

Durocher, D., J. Henckel, A.R. Fersht, and S.P. Jackson. 1999.
The FHA domain is a modular phosphopeptide recognition motif. Mol. Cell 4: 387-394.

Eck, M.J., S.K. Atwell, S.E. Shoelson, and S.C. Harrison. 1993. Recognition of a high-affinity phosphotyrosyl peptide by the Src homology-2 domain of p56lck. Nature 362: 87-91.

Ekman, S., E.R. Thuresson, C.-H. Heldin, and L. Rönnstrand, L. 1999. Increased mitogenecity of an $\alpha \beta$ heterodimeric PDGF receptor complex correlates with lack of RasGAP binding. Oncogene 18: 1-8.

Elion, E.A. 1998. Routing MAP kinase cascades. Science 281: $1625-1626$.

Etemad-Moghadam, B., S. Guo, and K.J. Kemphues. 1995. Asymmetrically distributed PAR-3 protein contributes to cell polarity and spindle alignment in early C. elegans embryos. Cell 83: 743-752.

Fagotto, F., E. Jho, L. Zeng, T. Kurth, T. Joos, C. Kaufmann, and F. Costantini. 1999. Domains of axin involved in proteinprotein interactions, Wnt pathway inhibition, and intracellular localization. J. Cell Biol. 145: 741-756.

Fambrough, D., K. McClure, A. Kazlauskas, and E.S. Lander. 1999. Diverse signaling pathways activated by growth factor receptors induce broadly overlapping, rather than independent, sets of genes. Cell 97: 727-741.

Fanning, A.S. and J.M. Anderson. 1999. Protein modules as organizers of membrane structure. Curr. Opin. Cell. Biol. 11: 432-439.

Flanagan, J.G. and P. Vanderhaeghen. 1998. The ephrins and Eph receptors in neural development. Annu. Rev. Neurosci. 21: 309-345.

Frise, E., J.A. Knoblich, S. Younger-Shepherd, L.Y. Ja, and Y.N. Jan. 1996. The Drosophila Numb protein inhibits signaling of the Notch receptor during cell-cell interaction in sensory organ lineage. Proc. Natl. Acad. Sci. 93: 11925-11932.

Fruman, D.A., L.E. Rameh, and L.C. Cantley. 1999. Phosphoinositide binding domains: Embracing 3-phosphate. Cell 97: 817-820.

Gassmann, M., F. Casagranda, D. Orioli, H. Simon, C. Lai, R. Klein, and G. Lemke. 1995. Aberrant neural and cardiac development in mice lacking the erbB4 neuregulin receptor. Nature 378: 390-394.

Gavin, A.C. and A.R. Nebreda. 1999. A MAP kinase decking site is required for phosphorylation and activation of $\mathrm{p} 90(\mathrm{rsk}) /$ MAPKAP kinase-1. Curr. Biol. 9: 281-284.

Gertler, F.B., K. Niebuhr, M. Reinhard, J. Wehland, and P. Soriano. 1996. Mena, a relative of VASP and Drosophila enabled, is implicated in the control of microfilament dynamics. Cell 87: 227-239.

Hart, M., J.P. Concordet, I. Lassot, I. Albert, R. del los Santos, H. Durand, C. Perret, B. Rubinfeld, F. Margottin, R. Benarous et al 1999. The F-box protein $\beta$-TrCP associates with phosphorylated $\beta$-catenin and regulates its activity in the cell. Curr. Biol. 9: 207-210.

Heldin, C.H. 1995. Dimerization of cell surface receptors in signal transduction. Cell 80: 213-223.

Heldin, C.-H., A. Östman, and L. Rönnstrand. 1998. Signal transduction via platelet-derived growth factor receptors. Biochim. Biophys. Acta 1378: F79-F113.

Heuchel, R., A. Berg, M. Tallquist, K. Ahlen, R.K. Reed, K. Rubin, L. Claesson-Welsh, C.H. Heldin, and P. Soriano. 1999. Platelet-derived growth factor $\beta$ receptor regulates interstitial fluid homeostasis through phosphatidylinositol-3' kinase signaling. Proc. Natl. Acad. Sci. 96: 11410-11415.

Hillier, B.J., K.S. Christopherson, K.E. Prehoda, D.S. Bredt, and W.A. Lim. 1999. Unexpected modes of PDZ domain scaffolding revealed by structure of nNOS-syntrophin complex. Sci- 
ence 284: 812-815.

Hing, H., J. Xiao, N. Harden, L. Lim, and S.L. Zipursky. 1999. Pak functions downstream of Dock to regulate photoreceptor axon guidance in Drosophila. Cell 97: 853-863.

Hof, P., S. Pluskey, S. Dhe-Paganon, M.J. Eck, and S.E. Shoelson. 1998. Crystal structure of the tyrosine phosphatase SHP-2. Cell 92: 441-450.

Hofmann, K. and P. Butcher. 1995. The FHA domain: A putative nuclear signalling domain found in protein kinases and transcription factors. Trends Biochem. Sci. 20: 347-349.

Holder, N. and R. Klein. 1999. Eph receptors and ephrins: Effectors of morphogenesis. Development 126: 2033-2044.

Holland, P.M. and J.A. Cooper. 1999. Protein modification: Docking sites for kinases. Curr. Biol. 9: R329-R331.

Holland, S.J., N.W. Gale, G.D. Gish, R.A. Roth, Z. Songyang, L.C. Cantley, M. Henkemeyer, G.D. Yancopoulos, and T. Pawson. 1997. Juxtamembrane tyrosine residues couple the Eph family receptor Eph B2/Nuk to specific SH2 domain proteins in neuronal cells. EMBO T. 16: 3877-3888.

Hong, K., L. Hinck, M. Nishiyama, M.M. Poo, M. Tessier-Lavigne, and E. Stein. 1999. A ligand-gated association between cytoplasmic domains of UNC5 and DCC family receptors converts netrin-induced growth cone attraction to repulsion. Cell 97: 927-941.

Hsu, H., J. Xiong, and D.V. Goeddel. 1995. The TNF receptor 1 -associated protein TRADD signals cell death and NFkappa B activation. Cell 81: 495-504.

Huang, D., J. Moffat, W.A. Wilson, L. Moore, C. Cheng, P.J. Roach, and B. Andrews. 1998. Cyclin partners determine Pho85 protein kinase substrate specificity in vitro and in vivo: Control of glycogen biosynthesis by Pcl8 and Pcl10. Mol. Cell. Biol. 18: 3289-3299.

Hubbard, S.R. 1999. Structural analysis of receptor tyrosine kinases. Prog. Biophys. Mol. Biol. 71: 343-358.

Hunter, T. 2000. Signaling-2000 and beyond. Cell 100: 113 127.

Itoh, K., A. Antipova, M.J. Ratcliffe, and S. Sokol. 2000. Interaction of dishevelled and xenopus axin-related protein is required for Wnt signal transduction. Mol. Cell. Biol. 20: 2228-2238.

Jacobs, D., D. Glossip, H. Xing, A.J. Muslin, and K. Kornfeld. 1999. Multiple docking sites on substrate proteins form a modular system that mediates recognition by ERK MAP kinase. Genes \& Dev. 13: 163-175.

Joazerio, C.A., S.S. Wing, H. Huang, J.D. Leverson, T. Hunter, and Y.C. Liu. 1999. The tyrosine kinase negative regulator c-Cbl as a RING-type, E2-dependent ubiquitin-protein ligase. Science 286: 309-312.

Kaffitz, K.W., C.R. Rose, H. Thoenen, and A. Konnerth. 1999. Neurotrophin-evoked rapid excitation through TrkB receptors. Nature 401: 918-921.

Kalo, M.S. and E.B. Pasquale. 1999. Multiple in vivo tyrosine phosphorylation sites in EphB receptors. Biochemistry 38: 14396-14408.

Karin, M. 1999. The beginning of the end ІкB kinase (IKK) and NF-кB activation. J. Biol. Chem. 274: 27339-27342.

Kawata, T., A. Shevchenko, M. Fukuzawa, K.A. Jermyn, N.F. Totty, N.V. Zhukovskaya, A.E. Sterling, M. Mann, and J.G. Williams. 1997. SH2 signaling in a lower eukaryote: A STAT protein that regulates stalk cell differentiation in dictyostelium. Cell 89: 909-916.

Kay, L.E., D.R. Muhandiram, G. Wolf, S.E. Shoelson, and J.D. Forman-Kay. 1998. Correlation between binding and dynamics at SH2 domain interfaces. Nat. Struct. Biol. 5: 156-163.

Kelkar, N., S. Gupta, M. Dickens, and R.J. Davis. 2000. Inter- action of a mitogen-activated protein kinase signaling module with the neuronal protein JIP3. Mol. Cell Biol. 20: 10301043.

Kidd, T., K. Brose, K.J. Mitchell, R.D. Fetter, M. Tessier-Lavigne, C.S. Goodman, and G. Tear. 1998. Roundabout controls axon crossing of the CNS midline and defines a novel subfamily of evolutionarily conserved guidance receptors. Cell 92: 205-215.

Kidd, T., K.S. Bland, and C.S. Goodman. 1999. Slit is the midline repellent for the robo receptor in Drosophila. Cell 96: 785794.

Kissel, H., I. Timokhina, M.P. Hardy, G. Rothschild, Y. Tajima, V. Soares, M. Angeles, S.R. Whitlow, K. Manova, and P. Besmer. 2000. Point mutation in Kit receptor tyrosine kinase reveals essential roles for Kit signaling in spermatogenesis and oogenesis without affecting other Kit responses. EMBO J. 19: 1312-1326.

Klein, G. and E. Klein. 1998. Sinking surveillance's flagship. Nature 395: 443-443.

Kouhara, H., Y.R. Hadari, T. Spivak-Kroizman, J. Schilling, D. Bar-Sagi, I. Lax, and J. Schlessinger. 1997. A lipid-anchored Grb2-binding protein that links FGF-receptor activation to the Ras/MAPK signaling pathway. Cell 89: 693-702.

Kretzschmar, M., J. Doody, I. Timokhina, and J. Massague. 1999. A mechanism of repression of TGF $\beta /$ Smad signaling by oncogenic Ras. Genes \& Dev. 13: 804-816.

Kuriyan, J. and D. Cowburn. 1997. Modular peptide recognition domains in eukaryotic signaling. Annu. Rev. Biophys. Biomol. Struct. 26: 259-288.

Lanier, L.M. and F.B. Gertler. 2000. From Abl to actin: Abl tyrosine kinase and associated proteins in growth cone motility. Curr. Opin. Neurobiol. 10: 80-87.

Lanier, L.M., M.A. Gates, W. Witke, A.S. Menzies, A.M. Wehman, J.D. Macklis, D. Kwiatkowski, P. Soriano, and F.B. Gertler. 1999. Mena is required for neurulation and commissure formation. Neuron 22: 313-325.

Larose, L., G. Gish, and T. Pawson. 1995. Construction of an SH2 domain-binding site with mixed specificity. J. Biol. Chem. 270: 3858-3862.

Lee, K.F., H. Simon, H. Chen, B. Bates, M.C. Hung, and C. Hauser. 1995. Requirement for neuregulin receptor erbB2 in neural and cardiac development. Nature 378: 394-398.

Leonardo, E.D., L. Hinck, M. Masu, K. Keino-Masu, S.L. Ackerman, and M. Tessier-Lavigne. 1997. Vertebrate homologues of C. elegans UNC-5 are candidate netrin receptors. Nature 386: 833-838.

Lesa, G.M. and P.W. Sternberg. 1997. Positive and negative tissue-specific signaling by a nematode epidermal growth factor receptor. Mol. Cell. Biol. 8: 779-793.

Leuing-Hagesteijn, C., A.M. Spence, B.D. Stern, Y. Zhou, M.W. Su, E.M. Hedgecock, and J.G. Culotti. 1992. UNC-5, a transmembrane protein with immunoglobulin and thrombospondin type 1 domains, guides cell and pioneer axon migration in C. elegans. Cell 71: 289-299.

Li, N., A. Batzer, R. Daly, E. Skolnik, P. Chardin, D. Bar-Sagi, B. Margolis, and J. Schlessinger. 1993. Guanine nucleotide releasing factor hSos1 binds to Grb2 and links receptor tyrosine kinases to Ras signaling. Nature 363: 85-88.

Li, S.C., C. Zwahlen, S.J. Vincent, C.J. McGlade, L.E. Kay, T. Pawson, and J.D. Forman-Kay. 1998. Structure of a Numb PTB domain-peptide complex suggests a basis for diverse binding specificity. Nat. Struct. Biol. 5: 1075-1083.

Li, S.C., G. Gish, D. Yang, A.J. Coffey, J.D. Forman-Kay, I. Ernberg, L.E. Kay, and T. Pawson. 1999. Novel mode of ligand binding by the SH2 domain of the human XLP disease gene 
product SAP/SH2D1A. Curr. Biol. 9: 1355-1362.

Liao, H., I.J. Byeon, and M.D. Tsai. 1999. Structure and function of a new phosphopeptide-binding domain containing the FHA2 of Rad53. J. Mol. Biol. 294: 1041-1049.

Lin, D., G.D. Gish, Z. Songyang, and T. Pawson. 1999. The carboxyl terminus of B class ephrins constitutes a PDZ domain binding motif. J. Biol. Chem. 274: 3726-3733.

Liu, F., Q. Wan, Z.B. Pristupa, X.-M. Yu, Y.T. Wang, and H.B. Niznik. 2000. Direct protein-protein coupling enables crosstalk between dopamine D5 and $\gamma$-aminobutyric acid A receptors. Nature 403: 274-280.

Liu, S.K., N. Fang, G.A. Koretzky, and C.J. McGlade. 1999. The hematopoietic-specific adaptor protein gads functions in $\mathrm{T}$ cell signaling via interactions with the SLP-76 and LAT adaptors. Curr. Biol. 9: 67-75.

Lowman, H.B., B.C. Cunnigham, and J.A. Wells. 1991. Mutational analysis and protein engineering of receptor-binding determinants in human placental lactogen. J. Biol. Chem. 266: 10982-10988.

Lu, P.J., X.Z. Zhou, M. Shen, and K.P. Lu. 1999. Function of WW domains as phosphoserine- or phosphothreonine-binding modules. Science 283: 1325-1328.

Lu, W., S. Katz, R. Gupta, and B.J. Mayer. 1997. Activation of Pak by membrane localization mediated by an SH3 domain from the adaptor protein Nck. Curr. Biol. 7: 85-94.

Maina, F., F. Casagranda, E. Andero, A. Simeone, P.M. Comoglio, G. Klein, and C. Ponzetto. 1996. Uncoupling of Grb2 from the Met receptor in vivo reveals complex roles in muscle development. Cell 87: 531-542.

Manser, E., T.H. Loo, C.G. Koh, Z.S. Zhao, X.Q. Chen, I. Tan, T. Leung, and L. Lim. 1998. PAK kinases are directly coupled to the PIX family of nucleotide exchange factors. Mol. Cell 1: 183-192.

Mao, Y., A. Nickitenko, X. Duan, T.E. Lloyd, M.N. Wu, H. Bellen, and F.A. Quiocho. 2000. Crystal structure of the VHS and FYVE tandem domains of Hrs a protein involved in membrane trafficking and signal transduction. Cell 100: 447-456.

Marengere, L.E.M., Z. Songyang, G.D. Gish, M.D. Schaller, T. Parsons, M.J. Stern, L.C. Cantley, and T. Pawson. 1994. SH2 domain specificity and activity modified by a single residue. Nature 369: 502-505.

Marshall, C.J. 1994. MAP kinase kinase kinase, MAP kinase kinase and MAP kinase MAP kinase. Curr. Opin. Genet. Dev. 4: 82-89.

Massague, J. 1998. TGF- $\beta$ signal transduction. Annu. Rev. Biochem. 67: 753-791.

Mayer, B.J. 1999. Endocytosis: EH domains lend a hand. Curr. Biol. 9: R70-R73.

McWhirter, S.M., S.S. Pullen, J.M. Holton, J.J. Crute, M.R. Kehry, and T. Alber. 1999. Crystallographic analysis of CD40 recognition and signaling by human TRAF2. Proc. Natl. Acad. Sci. 96: 8408-8412.

Meyer, D. and C. Birchmeier. 1995. Multiple essential functions of neuregulin in development. Nature 378: 386-390.

Meyer, D., A. Liu, and B. Margolis. 1999. Interaction of c-Jun amino-terminal kinase interacting protein-1 with p190rhoGEF and its localization in differentiated neurons. J. Biol. Chem. 274: 35113-35118.

Muslin, A.J., J.W. Tanner, P.M. Allen, and A.S. Shaw. 1996. Interaction of 14-3-3 with signaling proteins is mediated by the recognition of phosphoserine. Cell 84: 889-897.

Muzio, M., A.M. Chinnaiyan, F.C. Kischkel, K. O'Rourke, A. Shevchenko, J. Ni, C. Scaffidi, J.D. Bretz, M. Zhang, R. Gentz, M. Mann, P.H. Krammer, M.E. Peter, and V.M. Dixit.
1996. FLICE, a novel FADD-homologous ICE/CED-3-like protease, is recruited to the CD95 (Fas/APO-1) death-inducing signaling complex. Cell 85: 817-827.

Nebreda, A.R. and A.C. Gavin. 1999. Cell survival demands some Rsk. Science 286: 1309-1310.

Newlon, M.G., M. Roy, D. Morikis, Z.E. Hausken, V. Coghlan, J.D. Scott, and P.A. Jennings. 1999. The molecular basis for protein kinase A anchoring revealed by solution NMR. Nat. Struct. Biol. 6: 222-227.

Nguyen, J.T., C.W. Turck, F.E. Cohen, R.N. Zuckermann, and W. Lim. 1998. Exploiting the basis of proline recognition by SH3 and WW domains: Design of N-substituted inhibitors. Science 282: 2088-2092.

Niebuhr, K., F. Ebel, R. Frank, M. Reinhard, F. Domann, U.D. Carl, U. Walter, F.B. Gertler, J. Wehland, and T. Chakraborty. 1997. A novel proline-rich motif present in ActA of Listeria monocytogenes and cytoskeletal proteins is the ligand for the EVH1 domain, a protein module present in the Ena/VASP family. EMBO J. 16: 5433-5444.

Nishita, M., M.K. Hashimoto, S. Ogata, M.N. Laurent, N. Ueno, H. Shibuya, and K.W. Cho. 2000. Interaction between Wnt and TGF- $\beta$ signalling pathways during formation of Spemann's organizer. Nature 403: 781-785.

Ong, S.H., G.R. Guy, Y.R. Hadari, S. Laks, N. Gotoh, J. Schlessinger, and I. Lax. 2000. FRS2 proteins recruit intracellular signaling pathways by binding to diverse targets on fibroblast growth factor and nerve growth factor receptors. Mol. Cell. Biol. 20: 979-989.

Ottinger, E.A., M.C. Botfield, and S.E. Shoelson. 1998. Tandem SH2 domains confer high specificity in tyrosine kinase signaling. J. Biol. Chem. 273: 729-735.

Park, Y.C., V. Burkit, A.R. Villa, L. Tong, and H. Wu. 1999. Structural basis for self-association and receptor recognition of human TRAF2. Nature 398: 533-538.

Pascal, S.M., A.U. Singer, G. Gish, T. Yamazaki, S.E. Shoelson, T. Pawson, L.E. Kay, and J.D. Forman-Kay. 1994. Nuclear magnetic resonance structure of an $\mathrm{SH} 2$ domain of phospholipase C-gammal complexed with a high affinity binding peptide. Cell 77: 461-472.

Patton, E.E., A.R. Willems, D. Sa, L. Kuras, D. Thomas, K.L. Craig, and M. Tyers. 1998. Cdc53 is a scaffold protein for multiple Cdc34/Skp1/F-box protein complexes that regulate cell division and methionine biosynthesis in yeast. Genes \& Dev. 12: 692-705.

Pawson, T. 1995. Protein modules and signalling networks. $\mathrm{Na}$ ture 373: 573-580.

Pawson, T. and J.D. Scott. 1997. Signaling through scaffold, anchoring, and adaptor proteins. Science 278: 2075-2080.

Pellicena, P., K.R. Stowen, and W.T. Miller. 1998. Enhanced phosphorylation of src family kinase substrates containing SH2 domain binding sites. J. Biol. Chem. 273: 15325-15328.

Peng, C.Y., P.R. Graves, R.S. Thoma, Z. Wu, A.S. Shaw, and H. Piwnica-Worms. 1997. Mitotic and G2 checkpoint control: Regulation of 14-3-3 protein binding by phosphorylation of Cdc25C on serine-216. Science 277: 1501-1505.

Pinkas-Kramarski, R., M. Shelly, B.C. Guarino, L.M. Wang, L. Lyass, I. Alroy, M. Alamand, A. Kuo, J.D. Moyer, S. Lavi, M. Eisenstein, B.J. Ratzkin, R. Seger, S.S. Bacus, J.H. Pierce, G.C. Andrews, and Y. Yarden. 1998. ErbB tyrosine kinases and the two neuregulin families constitute a ligand-receptor network. Mol. Cell. Biol. 18: 6090-6101.

Plotnikov, A.N., J. Schlessinger, S.R. Hubbard, and M. Mohammadi. 1999. Structural basis for FGF receptor dimerization and activation. Cell 98: 641-650.

Plowman, G.D., S. Sudarsanam, J. Bingham, D. Whyte, and T. 
Hunter. 1999. The protein kinases of Caenorhabditis elegans: A model for signal transduction in multicellular organisms. Proc. Natl. Acad. Sci. 96: 13603-13610.

Posas, F. and H. Saito. 1997. Osmotic activation of the HOG MAPK pathway via Ste11p MAPKKK: Scaffold role of Pbs2p MAPKK. Science 276: 1702-1705.

Poy, F., M.B. Yaffe, J. Sayos, K. Saxena, M. Morra, J. Sumegi, L.C. Cantley, C. Terhorst, and M.J. Eck. 1999. Crystal structures of the XLP Protein SAP reveal a class of SH2 domains with extended, phosphotyrosine-independent sequence recognition. Mol. Cell 4: 555-561.

Prehoda, K.E., D.J. Lee, and W.A. Lim. 1999. Structure of the enabled/VASP homology 1 domain-peptide complex: A key component in the spatial control of actin assembly. Cell 97: 471-480.

Pryciak, P.M. and F.A. Huntress. 1998. Membrane recruitment of the kinase cascade scaffold protein Ste5 by the G $\beta \gamma$ complex underlies activation of the yeast pheromone response pathway. Genes \& Dev. 12: 2684-2697.

Qin, B., S.S. Lam, and K. Lin. 1999. Crystal structure of a transcriptionally active Smad4 fragment. Struct. Fold Des. 7: 1493-1503.

Radhakrishnan, I., G.C. Perez-Alvarado, D. Parker, H.J. Dyson, M.R. Montminy, and P.E. Wright. 1997. Solution structure of the KIX domain of CBP bound to the transactivation domain of CREB: A model for activator-coactivator interactions. Cell 91: 741-752.

Rameh, L.E. and L.C. Cantley. 1999. The role of phosphoinositide 3-kinase lipid products in cell function. J. Biol. Chem. 274: 8347-8350.

Remy, I., I.A. Wilson, and S.W. Michnick. 1999. Erythropoietin receptor activation by a ligand-induced conformation change. Science 283: 990-993.

Rhyu, M.S., L.Y. Jan, and Y.N. Jan. 1994. Asymmetric distribution of numb protein during division of the sensory organ precursor cell confers distinct fates to daughter cells. Cell 76: 477-491.

Richards, S.A., J. Fu, A. Rommanelli, A. Shimamura, and J. Blenis. 1999. Ribosomal S6 kinase 1 (RSK1) activation requires signals dependent on and independent of the MAP kinase ERK. Curr. Biol. 9: 810-820.

Rothe, M., S.C. Wong, W.J. Henzel, and D.V. Goeddel. 1994. A novel family of putative signal transducers associated with the cytoplasmic domain of the $75 \mathrm{kDa}$ tumor necrosis factor receptor. Cell 78: 681-692.

Rothwarf, D.M., E. Zandi, G. Natoli, and M. Karin. 1998. IKK- $\gamma$ is an essential regulatory subunit of the ІкB kinase complex. Nature 395: 297-300.

Rozakis-Adcock, M., R. Fernley, J. Wade, T. Pawson, and D. Bowtell. 1993. The SH2 and SH3 domains of mammalian Grb2 couple the EGF-receptor to mSos1, an activator of Ras. Nature 363: 83-85.

Sakai, R., A. Iwamatsu, N. Hirano, S. Ogawa, T. Tanaka, H. Mano, Y. Yazaki, and H. Hirai. 1994. A novel signal-assembler molecule, p130, forms stable complexes in vivo with $\mathrm{v}$-Crk and $\mathrm{v}$-Src in a tyrosine phosphorylation-dependent manner. EMBO J. 13: 3748-3756.

Salcini, A.E., S. Confalonieri, M. Doria, E. Santolini, E. Tassi, O. Minenkova, G. Cesareni, P.G. Pelicci, and P.P. Di Fiore. 1997. Binding specificity and in vivo targets of the EH domain, a novel protein-protein interaction module. Genes \& Dev. 11: 2239-2249.

Salvesen, G.S. and V.M. Dixit. 1999. Caspase activation: The induced-proximity model. Proc. Natl. Acad. Sci. 96: 1096410967.
Sanders, L.C., F. Matsumura, G.M. Bokoch, and P. de Lanerolle. 1999. Inhibition of myosin light chain kinase by p21-activated kinase. Science 283: 2083-2085.

Sayos, J., C. Wu, M. Morra, N. Wang, X. Zhang, D. Allen, S. van Schaik, L. Notarangelo, R. Geha, M.G. Roncarolo et al. 1998. The X-linked lymphoproliferative-disease gene product SAP regulates signals induced through the co-receptor SLAM. Nature 395: 462-469.

Schober, M., M. Schefer, and J.A. Knoblich. 1999. Bazooka recruits inscuteable to orient asymmetric cell division in Drosophila neuroblasts. Nature 402: 548-551.

Schulman, B.A., D.L. Lindstrom, and E. Harlow. 1998. Substrate recruitment to cyclin-dependent kinase 2 by a multipurpose docking site on cyclin A. Proc. Natl. Acad. Sci. 95: 1045310458.

Schultz, J., R.R. Copley, T. Doerks, C.P. Ponting, and P. Bork. 2000. SMART: A web-based tool for the study of genetically mobile domains. Nucleic Acids Res. 28: 231-234.

Sicheri, F., I. Moarefi, and J. Kuriyan. 1997. Crystal structure of the Src family tyrosine kinase Hck. Nature 385: 602-609.

Skowyra, D., K.L. Craig, M. Tyers, S.J. Elledge, and J.W. Harper. 1997. F-box proteins are receptors that recruit phosphorylated substrates to the SCF ubiquitin-ligase complex. Cell 91: 209-219.

Song, H., G. Ming, Z. He, M. Lehmann, L. McKerracher, M. Tessier-Lavigne, and M. Poo. 1998. Conversion of neuronal growth cone responses from repulsion to attraction by cyclic nucleotides. Science 281: 1515-1518.

Songyang, Z., S.E. Shoelson, M. Chadhuri, G. Gish, T. Pawson, F. King, T. Roberts, S. Ratnofsky, B. Schaffhausen, and L.C. Cantley. 1993. Identification of phosphotyrosine peptide motifs which bind to SH2 domains. Cell 72: 767-778.

Songyang, Z., G. Gish, G. Mbamalu, T. Pawson, and L.C. Cantley. 1995. A single point mutation switches the specificity of group III Src homology (SH)2 domains to that of group I SH2 domains. J. Biol. Chem. 270: 26029-26032.

Songyang, Z., A.S. Fanning, C. Fu, J. Xu, S.M. Marfatia, A.H. Chishti, A. Crompton, A.C. Chan, J.M. Anderson, and L.C. Cantley. 1997. Recognition of unique carboxyl-terminal motifs by distinct PDZ domains. Science 275: 73-77.

Stapleton, D., I. Balan, T. Pawson, and F. Sicheri. 1999. The crystal structure of an Eph receptor SAM domain reveals a mechanism for modular dimerization. Nat. Struct. Biol. 6: 44-49.

Starr, R. and D.J. Hilton. 1999. Negative regulation of the JAK/ STAT pathway. BioEssays 21: 47-52.

Starr, R., T.A. Willson, E.M. Viney, L.J. Murray, J.R. Rayner, B.J. Jenkins, T.J. Gonda, W.S. Alexander, D. Metcalf, N.A. Nicola, and D.J. Hilton. 1997. A family of cytokine-inducible inhibitors of signalling. Nature 387: 917-921.

Steven, R., T. Kubiseski, H. Zheng, S. Kulkarni, J. Mancillas, A. Ruiz Morales, C.M.V. Hogue, T. Pawson, and J. Culotti. 1998. UNC-73 activates the Rac GTPase and is required for cell and growth cone migration in C. elegans. Cell 92: 785795.

Sun, X.J., D.L. Crimmins, M.G. Myers, M. Miralpeix, and M.F. White. 1993. Pleiotropic insulin signals are engaged by multisite phosphorylation of IRS-1. Mol. Cell. Biol. 13: 74187428.

Sun, Z., J. Hsiao, D.S. Fay, and D.F. Stern. 1998. Rad53 FHA domain associated with phosphorylated Rad9 in the DNA damage checkpoint. Science 281: 272-274.

Tabuse, Y., Y. Izumi, F. Piano, K.J. Kemphues, J. Miwa, and S. Ohno. 1998. Atypical protein kinase C cooperates with PAR-3 to establish embryonic polarity in Caenorhabditis 
elegans. Development 125: 3607-3614.

Tamagnone, L., S. Artigiani, H. Chen, Z. He, G.I. Ming, H. Song, A. Chedotal, M.L. Winberg, C.S. Goodman, M. Poo, M. Tessier-Lavigne, and P.M. Comoglio. 1999. Plexins are a large family of receptors for transmembrane, secreted, and GPI-anchored semaphorins in vertebrates. Cell 99: 71-80.

Tang, H.Y., J. Xu, and M. Cai. 2000. Panlp, End3p, and S1alp, three yeast proteins required for normal cortical actin cytoskeleton organization, associate with each other and play essential roles in cell wall morphogenesis. Mol. Cell. Biol. 20: $12-25$.

Tanoue, T., M. Adachi, T. Moriguchi, and E. Nishida. 2000. A conserved docking motif in MAP kinases common to substrates, activators and regulators. Nat. Cell. Biol. 2: 110-116.

Tessier-Lavigne, M. and C.S. Goodman. 1996. The molecular biology of axon guidance. Science 274: 1123-1133.

Thanos, C.D., K.E. Goodwill, and J.U. Bowie. 1999. Oligomeric structure of the human EphB2 receptor SAM domain. Science 283: 833-836.

Thorson, J.A., L.W. Yu, A.L. Hsu, N.Y. Shih, P.R. Graves, J.W. Tanner, P.M. Allen, H. Piwnica-Worms, and A.S. Shaw. 1998. 14-3-3 protein are required for maintenance of Raf-1 phosphorylation and kinase activity. Mol. Cell. Biol. 18: 5229-5238.

Trub, T., W.E. Choi, G. Wolf, E. Ottinger, Y. Chen, M. Weiss, and S.E. Sholeson. 1995. Specificity of the PTB domain of Shc for $\beta$ turn-forming pentapeptide motifs amino-terminal to phosphotyrosine. J. Biol. Chem. 270: 18205-18208.

Tsukazaki, T., T.A. Chiang, A.F. Davison, L. Attisano, and J.L. Wrana. 1998. SARA, a FYVE domain protein that recruits Smad2 to the TGF $\beta$ receptor. Cell 95: 779-791.

Tu, J.C., B. Xiao, S. Naisbitt, J.P. Yuan, R.S. Petralia, P. Brakeman, A. Doan, V.K. Aakalu, A.A. Lanahan, M. Sheng, and P.F. Worley. 1999. Coupling of mGluR/Homer and PSD-95 complexes by the Shank family of postsynaptic density proteins. Neuron 23: 583-592.

Tyers, M. and A.R. Willems. 1999. One ring to rule a superfamily of E3 ubiquitin ligases. Science 284: 603-604.

Ulloa, L., J. Doody, and J. Massague. 1999. Inhibition of transforming growth factor- $\beta / S M A D$ signalling by the interferon$\gamma /$ STAT pathway. Nature 397: 710-713.

van der Geer, P., S. Wiley, V.K.M. Lai, J.P. Olivier, G.D. Gish, T. Stephens, D. Kaplan, S. Shoelson, and T. Pawson. 1995. A conserved amino-terminal SHC domain binds to activated growth factor receptors and phosphotyrosine-containing peptides. Curr. Biol. 5: 404-412.

van der Geer, P., S. Wiley, G.D. Gish, V.K. Lai, R. Stephens, M.F. White, D. Kaplan, and T. Pawson. 1996. Identification of residues that control specific binding of the Shc phosphotyrosine-binding domain to phosphotyrosine sites. Proc. Nat1. Acad. Sci. 93: 963-968.

Vetter, I.R., C. Nowak, T. Nishimoto, J. Kuhlmann, and A. Wittinghofer. 1999. Structure of a Ran-binding domain complexed with Ran bound to a GTP analogue: Implications for nuclear transport. Nature 398: 39-46.

Waksman, G., S.E. Shoelson, N. Pant, D. Cowburn, and J. Kuriyan. 1993. Binding of a high affinity phosphotyrosyl peptide to the Src SH2 domain: Crystal structures of the complexed and peptide-free forms. Cell 72:779-790.

Wasikiewicz, A.J., A. Flynn, C.G. Proud, and J.A. Cooper. 1997. Mitogen-activated protein kinases activate the serine/threonine kinases Mnk1 and Mnk2. EMBO J. 16:1909-1920.

Waterman, H., I. Alroy, S. Strano, R. Seger, and Y. Yarden. 1999. The C-terminus of the kinase-defective neuregulin receptor ErbB-3 confers mitogenic superiority and dictates endocytic routing. EMBO J. 18: 3348-3358.

Westphal, R.S., S.J. Tavalin, J.W. Lin, N.M. Alto, I.D. Fraser, L.K. Langeberg, M. Sheng, and J.D. Scott. 1999. Regulation of NMDA receptors by an associated phosphatase-kinase signaling complex. Science 285: 93-96.

Whitmarsh, A.J. and R.J. Davis. 1998. Structural organization of MAP-kinase signaling modules by scaffold proteins in yeast and mammals. Trends Biochem. Sci. 23: 481-485.

- 2000. A central control for cell growth. Nature 403: $255-256$.

Willems, A.R., S. Lanker, E.E. Patton, K.L. Craig, T.F. Nason, N. Mathias, R. Kobayashi, C. Wittenberg, and M. Tyers. 1996. Cdc53 targets phosphorylated G1 cyclins for degradation by the ubiquitin proteolytic pathway. Cell 86: 453-463.

Winston, J.T., P. Strack, P. Beer-Romero, C.Y. Chu, S.J. Elledge, and J.W. Harper. 1999. The SCF $\beta$-TCRP-ubiquitin ligase complex associates specifically with phosphorylated de-

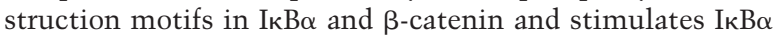
ubiquitination in vitro. Genes \& Dev. 15: 270-283.

Wodarz, A., A. Ramrath, U. Kuchinke, and E. Knust. 1999. Bazooka provides an apical cue for inscuteable localization in Drosophila neuroblasts. Nature 402: 544-547.

Wrana, J. 2000. Regulation of Smad activity. Cell 100: 189-192.

Wu, G., Y.G. Chen, B. Ozdamar, C.A. Gyuricza, P.A. Chong, J.L. Wrana, J. Massague, and Y. Shi. 2000. Structural basis of Smad2 recognition by the Smad anchor for receptor activation. Science 287: 92-97.

Wu, H., U. Klingmuller, P. Besmer, and H.F. Lodish. 1995. Interaction of the erythropoietin and stem-cell-factor receptors. Nature 377: 242-246.

Xing, H., S. Zhang, C. Weinheimer, A. Kovacs, and A.J. Muslin. 2000. 14-3-3 proteins block apoptosis and differentially regulate MAPK cascades. EMBO J. 19: 349-358.

Xing, J., D.D. Ginty, and M.E. Greenberg. 1996. Coupling of the RAS-MAPK pathway to gene activation by RSK2, a growth factor-regulated CREB kinase. Science 273: 959-963.

Xu, W., S.C. Harrison, and M.J. Eck. 1997. Three-dimensional structure of the tyrosine kinase c-Src. Nature 385: 595-602.

Yaffe, M.B., K. Rittinger, S. Volina, P.R. Caron, A. Aitken, H. Leffers, S.J. Gamblin, S.J. Smerdon, and L.C. Cantley. 1997. The structural basis for 14-3-3:phosphopeptide binding specificity. Cell 91: 961-971.

Yaron, A., A. Hatzubai, M. Davis, I. Lavon, S. Amit, A.M. Manning, J.S. Andersen, M. Mann, F. Mercurio, and Y. Ben-Neriah. 1998. Identification of the receptor component of the ІкB $\alpha$-ubiquitin ligase. Nature 396: 590-594.

Yasuda, J., A.J. Whitmarsh, J. Cavanagh, M. Sharma, and R.J. Davis. 1999. The JIP group of mitogen-activated protein kinase scaffold proteins. Mol. Cell. Biol. 19: 7245-7254.

Ye, H., Y.C. Park, M. Kreishman, E. Kieff, and H. Wu. 1999. The structural basis for the recognition of diverse receptor sequences by TRAF2. Mol. Cell 4: 321-330.

Yoon, H.S., P.J. Hajduk, A.M. Petros, E.T. Olejczak, R.P. Meadows, and S.W. Fesik. 1994. Solution structure of a pleckstrinhomology domain. Nature 369: 672-675.

Zeng, L., F. Fagotto, T. Zhang, W. Hsu, T.J. Vasicek, W.L. Perry, III, J.J. Lee, S.M. Tilghman, B.M. Gumbiner, and F. Costantini. 1997. The mouse fused locus encodes axin, an inhibitor of the Wnt signaling pathway that regulates embryonic axis formation. Cell 90: 181-192.

Zeng, W., K.A. Wharton, Jr., J.A. Mack, K. Wang, M. Gadbaw, K. Suyama, P.S. Klein, and M.P. Scott. 2000. naked cuticle encodes an inducible antagonist of Wnt signalling. Nature 403: 789-795.

Zeng, Y. and H. Piwnica-Worms. 1999. DNA damage and rep- 
lication checkpoints in fission yeast require nuclear exclusion of the Cdc25 phosphatase via 14-3-3 binding. Mol. Cell. Biol. 19: 7410-7419.

Zeng, Y., K.C. Forbes, Z. Wu, S. Moreno, H. Piwnica-Worms, and T. Enoch. 1998. Replication checkpoint requires phosphorylation of the phosphatase Cdc25 by Cds1 or Chk1. Nature 395: 507-510.

Zha, J., H. Harada, E. Yang, J. Jockel, and S.J. Korsmeyer. 1996. Serine phosphorylation of death agonist BAD in response to survival factor results in binding to 14-3-3 not BCL- $\mathrm{X}_{\mathrm{L}}$. Cell 87: 619-628.

Zhang, J.G., A. Farley, S.E. Nicholson, T.A. Willson, L.M. Zugaro, R.J. Simpson, R.L. Mortiz, D. Cary, R. Richardson, G. Hausmann, B.J. Kile, S.B. Kent, W.S. Alexander, D. Metcalf, D.J. Hilton, N.A. Nicola, and M. Baca. 1999. The conserved SOCS box motif in suppressors of cytokine signaling binds to elongins $\mathrm{B}$ and $\mathrm{C}$ and may couple bound proteins to proteasomal degradation. Proc. Natl. Acad. Sci. 96: 20712076.

Zhou, M.-M., K.S. Ravichandran, E.T. Olejniczak, A.M. Petros, R.P. Meadows, M. Sattler, J.E. Harlan, W.S. Wade, S.J. Burakoff, and S.W. Fesik. 1995. Structure and ligand recognition of the phosphotyrosine binding domain of Shc. Nature 378: 584-592.

Zhu, H., P. Kavsak, S. Abdollah, J.L. Wrana, and G.H. Thomsen. 1999. A SMAD ubiquitin ligase targets the BMP pathway and affects embryonic pattern formation. Nature 400: 687693.

Zisch, A.H., C. Pazzagli, A.L. Freeman, M. Schneller, M. Hadman, J.W. Smith, E. Ruoslahti, and E.B. Pasquale. 2000. Replacing two conserved tyrosines of the EphB2 receptors with glutamic acid prevents binding of $\mathrm{SH} 2$ domains without abrogating kinase activity and biological responses. Oncogene 19: $177-187$. 


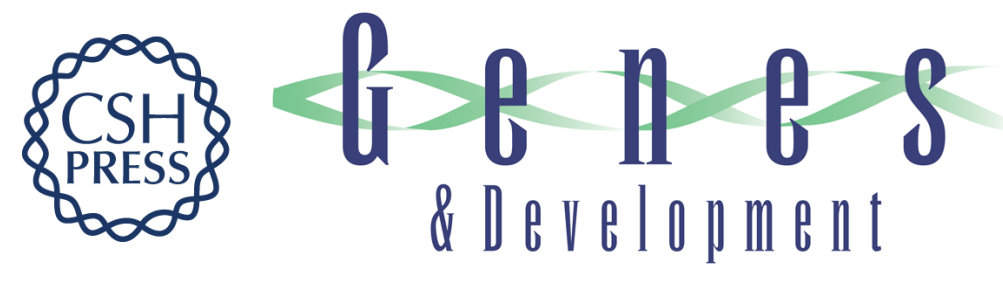

\section{Protein-protein interactions define specificity in signal transduction}

Tony Pawson and Piers Nash

Genes Dev. 2000, 14:

Access the most recent version at doi:10.1101/gad.14.9.1027

References This article cites 197 articles, 73 of which can be accessed free at: http://genesdev.cshlp.org/content/14/9/1027.full.html\#ref-list-1

License

Email Alerting Receive free email alerts when new articles cite this article - sign up in the box at the top Service right corner of the article or click here.

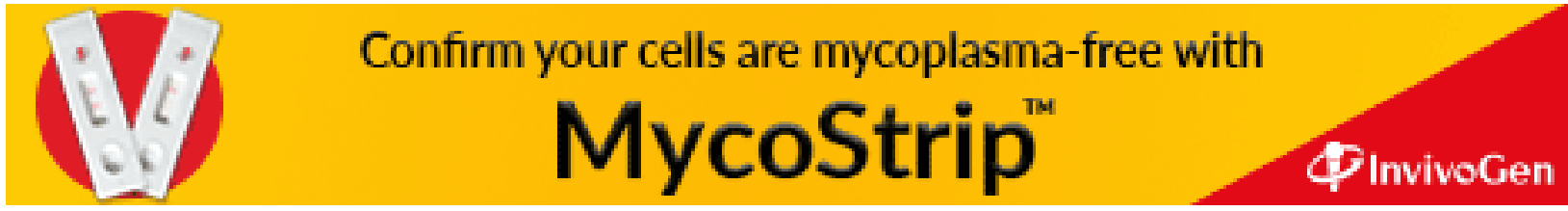

